\title{
Comparison of regional characteristics of land precipitation climatology projected by an MRI-AGCM multi-cumulus scheme and multi-SST ensemble with CMIP5 multi- model ensemble projections
}

\author{
Rui Ito ${ }^{1,2^{*}}$, Tosiyuki Nakaegawa ${ }^{2}$ and Izuru Takayabu ${ }^{2}$
}

\begin{abstract}
Ensembles of climate change projections created by general circulation models (GCMs) with high resolution are increasingly needed to develop adaptation strategies for regional climate change. The Meteorological Research Institute atmospheric GCM version 3.2 (MRI-AGCM3.2), which is listed in the Coupled Model Intercomparison Project phase 5 (CMIP5), has been typically run with resolutions of $60 \mathrm{~km}$ and $20 \mathrm{~km}$. Ensembles of MRI-AGCM3.2 consist of members with multiple cumulus convection schemes and different patterns of future sea surface temperature, and are utilized together with their downscaled data; however, the limited size of the high-resolution ensemble may lead to undesirable biases and uncertainty in future climate projections that will limit its appropriateness and effectiveness for studies on climate change and impact assessments. In this study, to develop a comprehensive understanding of the regional precipitation simulated with MRI-AGCM3.2, we investigate how well MRI-AGCM3.2 simulates the present-day regional precipitation around the globe and compare the uncertainty in future precipitation changes and the change projection itself between MRI-AGCM3.2 and the CMIP5 multiple atmosphereocean coupled GCM (AOGCM) ensemble. MRI-AGCM3.2 reduces the bias of the regional mean precipitation obtained with the high-performing CMIP5 models, with a reduction of approximately $20 \%$ in the bias over the Tibetan Plateau through East Asia and Australia. When 26 global land regions are considered, MRI-AGCM3.2 simulates the spatial pattern and the regional mean realistically in more regions than the individual CMIP5 models. As for the future projections, in 20 of the 26 regions, the sign of annual precipitation change is identical between the 50th percentiles of the MRI-AGCM3.2 ensemble and the CMIP5 multi-model ensemble. In the other six regions around the tropical South Pacific, the differences in modeling with and without atmosphere-ocean coupling may affect the projections. The uncertainty in future changes in annual precipitation from MRI-AGCM3.2 partially overlaps the maximum-minimum uncertainty range from the full ensemble of the CMIP5 models in all regions. Moreover, on average over individual regions, the projections from MRI-AGCM3.2 spread over roughly 0.8 of the uncertainty range from the high-performing CMIP5 models compared to 0.4 of the range of the full ensemble.
\end{abstract}

Keywords: Regional precipitation, Projection uncertainty, MRI-AGCM, CMIP5, Future climate change

\footnotetext{
* Correspondence: rui.ito@jmbsc.or.jp

'Japan Meteorological Business Support Center, 1-1 Nagamine, Tsukuba, Ibaraki 305-0052, Japan

${ }^{2}$ Meteorological Research Institute, Japan Meteorological Agency, 1-1 Nagamine, Tsukuba, Ibaraki 305-0052, Japan
}

\section{Springer Open}

(c) The Author(s). 2020 Open Access This article is licensed under a Creative Commons Attribution 4.0 International License, which permits use, sharing, adaptation, distribution and reproduction in any medium or format, as long as you give appropriate credit to the original author(s) and the source, provide a link to the Creative Commons licence, and indicate if changes were made. The images or other third party material in this article are included in the article's Creative Commons licence, unless indicated otherwise in a credit line to the material. If material is not included in the article's Creative Commons licence and your intended use is not permitted by statutory regulation or exceeds the permitted use, you will need to obtain permission directly from the copyright holder. To view a copy of this licence, visit http://creativecommons.org/licenses/by/4.0/. 


\section{Introduction}

To establish mitigation and adaptation strategies for future climate change, studies on climate change and assessment of its impacts have been conducted worldwide. These recent studies have frequently used future climate projections simulated by multiple general circulation models (GCMs) in the framework of the Coupled Model Intercomparison Project (CMIP); e.g., the CMIP phase 5 (CMIP5; Taylor et al. 2012). While the projections from GCMs and these study results are provided with $100-\mathrm{km}$ or coarser resolution, strategies must be developed for regional and local scales. Thus, there is a scale mismatch between these studies and stakeholders.

Dynamical and statistical downscaling techniques may be used to overcome the mismatch, yet confidence in the resulting scenarios is not always increased by the downscaling (Wilby and Dessai 2010; Hall 2014; Shepherd 2014). The downscaled climate information at a regional scale can include regional processes and the effects of complex terrain that GCMs cannot resolve. However, bias in the large-scale circulation simulated by GCMs leads to bias in the downscaled atmosphere from the GCM output (Hall 2014). Moreover, regional climate models (RCMs) cannot represent phenomena with large temporal or spatial scales beyond their boundaries nor phenomena that are not well-represented in GCMs, such as tropical cyclones. The spatial patterns of the regional precipitation climatology from downscaling experiments strongly depend on the pattern from GCMs (Šeparović et al. 2013) as do the regional future changes (Inatsu et al. 2015; Karmalkar 2018). Therefore, GCMs with sufficiently high horizontal resolution are required to simulate the climate realistically from global to regional scales. The added value obtained by using enhancedresolution GCMs for various climate variabilities (e.g., in reproducing large-scale circulation features like the El Niño-Southern Oscillation) has been reviewed by Haarsma et al. (2016).

The Meteorological Research Institute (MRI) of the Japan Meteorological Agency has been developing such a high-resolution GCM for more than 10 years (Mizuta et al. 2006). At present, the atmospheric GCM version 3.2 (MRI-AGCM3.2; Mizuta et al. 2012) is generally run with horizontal resolutions of $60 \mathrm{~km}$ and $20 \mathrm{~km}$ and has successfully simulated the global distribution of tropical cyclones (Yoshida et al. 2017) and regional characteristics such as the seasonal march of the East Asian monsoon (Kusunoki 2018). MRI-AGCM3.2 has been widely recognized as one of the GCMs participating in CMIP5 (IPCC 2013). In addition, the climate dataset generated by MRI-AGCM3.2 has been utilized in various international programs, for instance the Coordinated Regional Downscaling Experiment (CORDEX; https://www.cordex. org, Gutowski Jr. et al. 2016) in the World Climate
Research Program, and the CMIP6 project, the High Resolution Model Intercomparison Project (HighResMIP; Haarsma et al. 2016). In Japan, domestic impact assessments and adaptation measures are often based on the climate simulations by MRI-AGCM3.2.

Climate simulations by MRI-AGCM3.2 have been designed to reproduce well regional-scale climatology and extreme events with reasonable quality and then to investigate their future changes (Kitoh et al. 2016). Present-day climate simulations have been performed using an observed sea surface temperature (SST) dataset while future climate simulations have used various future change patterns of SST and sea ice estimated from the CMIP simulations. In general, prescription of observed SST in AGCM simulations can reduce SST bias and the consequent systematic bias in the present-day climate simulations relative to coupled atmosphereocean GCMs (AOGCMs). The feedback by the atmosphere-ocean coupling process, however, is not simulated in an AGCM, which can lead to distorted precipitation fields in some regions (He and Soden 2016; Kitoh et al. 2016). As well as the ensemble with different SST changes, an ensemble with different cumulus convection schemes has been created with the $60-\mathrm{km}$ resolution MRI-AGCM3.2 (MRI-AGCM3.2H) because the computational resources required are relatively small compared to the 20-km resolution MRI-AGCM3.2 (MRI-AGCM3.2S). Thus, the ensembles with MRI-AGCM3.2 can be used to assess future projections and their uncertainty arising from the differences in SST changes and model physics.

In addition to its good reproduction of tropical cyclones, the performance of MRI-AGCM has been investigated for climatology and extreme events on various spatial scales (e.g., Mizuta et al. 2012). Focusing on the assessment of simulated precipitation and its future change, Kusunoki (2017) indicated that MRI-AGCM3.2H performs well in simulating global precipitation, comparably to or better than atmospheric-MIP (AMIP) models in the CMIP5 archive. Kitoh and Endo (2016) and Mizuta et al. (2017) assessed global precipitation, including extreme weather events, using MRI-AGCM3.2S and MRI-AGCM3.2H, respectively. The high resolution of MRI-AGCM3.2 has allowed realistic simulations of regional precipitation (e.g., Endo et al. 2012, 2017; Kusunoki and Mizuta 2013; Ose 2017, 2019; Surendran et al. 2019). For instance, Endo et al. (2012) reported that MRI-AGCM3.2 at both resolutions realistically simulates the present-day precipitation over several areas in Asia, and discussed the contributions of SST changes and model physics to the uncertainty in future changes of regional precipitation using MRIAGCM3.2H. Okada et al. (2017) and Kusunoki (2018) evaluated the modeled seasonal march of the rain band that appears in the East Asian monsoon season. In addition, Okada et al. (2017) showed that the difference in 
the future SST patterns in the tropics affects the precipitation change over Japan using MRI-AGCM3.2S projections.

While the ability of MRI-AGCM to accurately represent precipitation climatology over the globe and specific regions has been demonstrated, a comprehensive understanding of its ability and the projections of future precipitation change in regions around the globe has yet to be established. Moreover, there has been insufficient discussion of the global and regional properties of the uncertainty in future projections with the MRI-AGCM3.2 ensemble. For impact assessments of climate change, information about the most severe situations is very useful. The MRIAGCM3.2 ensemble has a limited size of about 10 members due to its high horizontal resolution. The limitations of a small ensemble and also a single model may lead to an undesirably biased future projection with undesirably small uncertainty. The CMIP provides an ensemble of opportunity, although it is not completely clear that it provides the full uncertainty in climate projections (Knutti 2010). Thus, a comparison with the uncertainty from the CMIP ensemble is helpful to examine the limitations of the MRIAGCM3.2 ensemble and, furthermore, gives information about whether a single AGCM can cover the uncertainty from the CMIP ensemble.

In this study, we use a comparison with the CMIP5 ensemble to comprehensively evaluate the regional precipitation climatology over the globe simulated by MRIAGCM3.2. The precipitation climatology is the output most frequently analyzed in impact studies. To investigate the extent to which the MRI-AGCM3.2 projections are adequate for discussing regional precipitation changes, as well as projections of severe situation, our evaluation is conducted with respect to two points: how well does the simulated present-day precipitation represent the observations over individual regions, and to what degree does the MRI-AGCM3.2 ensemble capture the uncertainty in the future changes of regional precipitation projected with the CMIP5 multi-model ensemble (MME). Our principal purpose is to identify the characteristics of future changes and their uncertainty at a regional scale. Thus, we analyze the CMIP5 AOGCM ensemble throughout our analysis, instead of AMIP-type model simulations that are identical with the MRI-AGCM3.2 simulations. Evaluations of the present-day precipitation are conducted to identify model performance in representing the observations. Then, based on this performance, we create various subsets of the CMIP5 models and compare the future projections with them. In addition, comparisons between MRIAGCM3.2 and the CMIP5 AOGCMs can provide information on the advantage of forcing by observed SST for simulations at regional scale. Comparisons of the presentday precipitation between MRI-AGCM3.2 and AMIP models are given in the Supplementary Material.

\section{Methodology}

\subsection{Climatological dataset from MRI-AGCM3.2}

The climatological dataset used in this study is simulated using two horizontal resolutions of MRI-AGCM3.2 as described above. MRI-AGCM3.2H has a horizontal resolution of TL319 (triangular truncation at 319 waves; $~ 60$ $\mathrm{km})$ and 64 vertical layers with the top at $0.01 \mathrm{hPa}$, and MRI-AGCM3.2S has a resolution of TL959 $(\sim 20 \mathrm{~km})$ with the same vertical structure as MRI-AGCM3.2H. Three different cumulus convection parameterization schemes are implemented in MRI-AGCM3.2H: the Kain-Fritsch (KF) scheme (Kain and Fritsch 1990), the Arakawa-Schubert (AS) scheme (Randall and Pan 1993), and the Yoshimura (YS) scheme (Yoshimura et al. 2015). MRI-AGCM3.2S was only run using the YS scheme.

Present-day climate simulations are performed using the UK Met Office Hadley Centre's sea ice and SST dataset (HadISST1.1; Rayner et al. 2003) for historical SST and sea ice concentration observations. Future climate simulations are based on the representative concentration pathway (RCP) 8.5 scenario. Using spatial patterns of changes in SST and sea ice under the RCP8.5 scenario from the CMIP5 models, cluster analysis of the patterns produced three clusters of models. The SST change patterns $(\mathrm{C} 1-\mathrm{C} 3)$ corresponding to these three clusters and their mean $(\mathrm{C} 0)$ were estimated. Details of the analysis and the method of creating the four patterns are described in Mizuta et al. (2014). The four spatial patterns were applied to the future climate simulations with both resolutions of MRI-AGCM3.2. In sum, there are three (one) ensemble members for the present-day climate simulation from MRI-AGCM3.2H (MRIAGCM3.2S) and 12 (4) members for the future climate simulation. The spatial pattern of standard deviation of the four SST changes from C0 to C3 is shown in Fig. 1. Similar patterns were obtained for the annual mean and two seasonal means, June-August (JJA) and DecemberFebruary (DJF). There were large deviations in highlatitude regions as well as in the northwest regions of the Pacific and the Atlantic.

We computed annual mean precipitation $\mathrm{P}_{\mathrm{ANN}}$, boreal summer (JJA) mean precipitation $\mathrm{P}_{\mathrm{JJA}}$, and boreal winter (DJF) mean precipitation $\mathrm{P}_{\mathrm{DJF}}$ from monthly data over 20 years (1984-2003) for the present-day climate and 20 years of the late twenty-first century (2080-2099) for the RCP8.5 future climate scenario. In order to scale the future change of precipitation, annual mean surface air temperature (hereafter referred to as temperature) was also estimated. The ensemble members used are summarized in Table 1. The MRI-AGCM3.2H ensemble members for present-day and future climate are labeled HP and HF, respectively, and the MRI-AGCM3.2S members SP and SF. The scheme used by each member is specified 


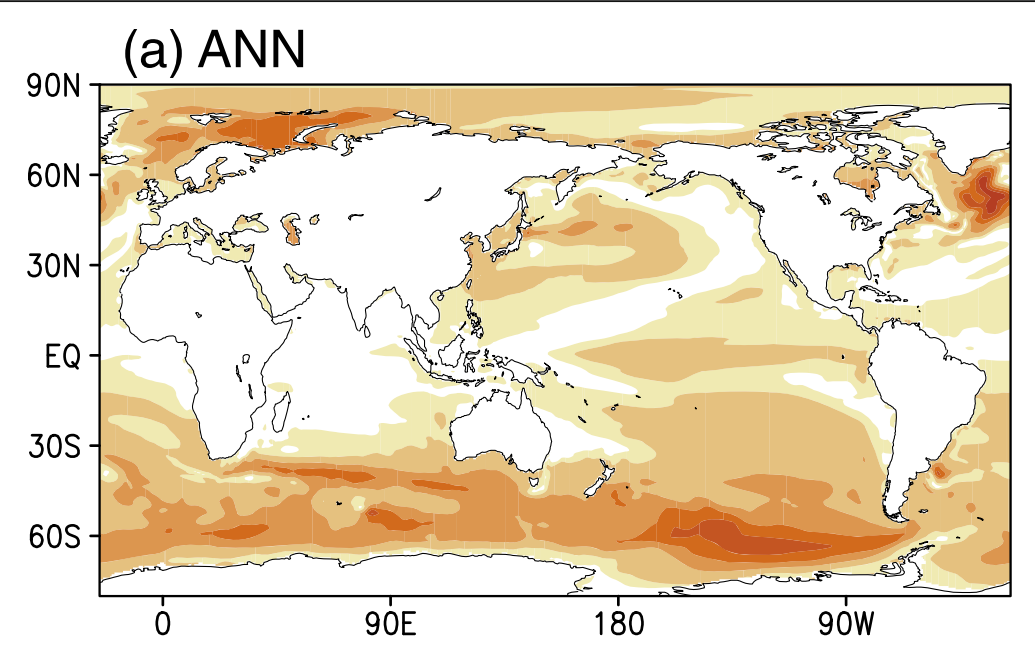

(b) JJA

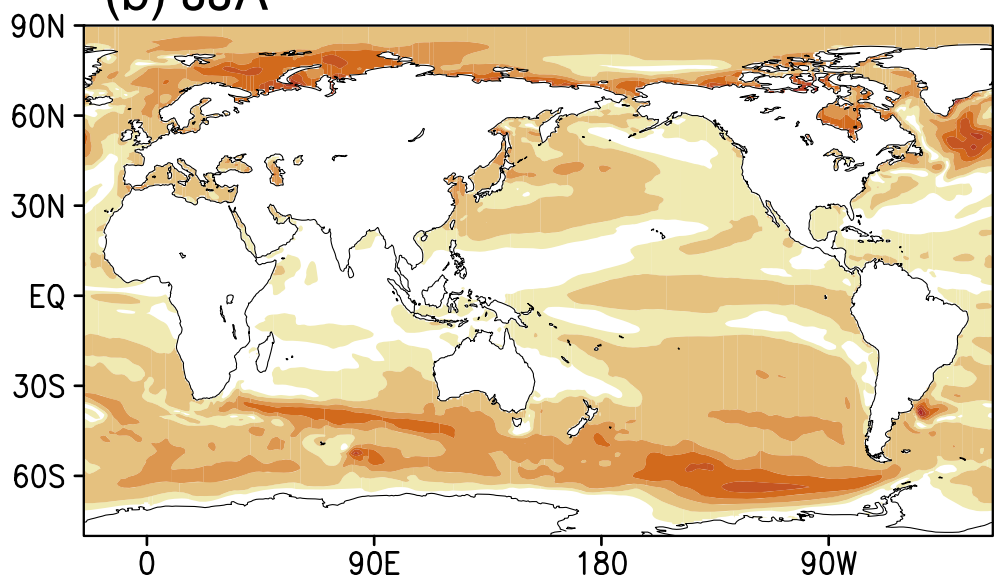

(c) DJF

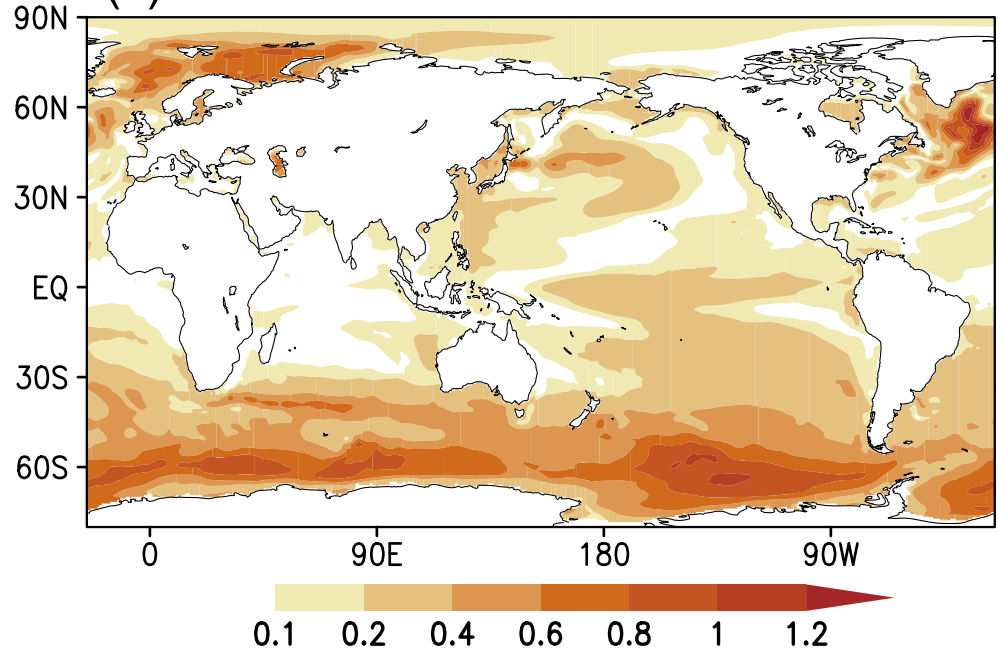

Fig. 1 Spatial pattern of standard deviation of four different SST change (K): three clusters and their mean. a Annual, b JJA, and c DJF

by adding the scheme name; for example, HPYS for the present-day simulation by HP with the YS scheme.

Regional characteristics were identified in each of 26 global land regions. The classification of the regions follows the definition in the IPCC Special Report on Managing the Risks of Extreme Events and Disasters to Advance Climate Change Adaptation (IPCC SREX; IPCC 2012) and is illustrated here in Fig. 2. As in IPCC (2012), 
Table 1 MRI-AGCM ensemble members

\begin{tabular}{|c|c|c|c|c|}
\hline \multicolumn{2}{|c|}{ Member name ${ }^{a}$} & Model & $\begin{array}{c}\text { Horizontal } \\
\text { resolution }\end{array}$ & $\begin{array}{c}\text { Cumulus convection } \\
\text { scheme }\end{array}$ \\
\hline Present-day & $\begin{array}{l}\text { RCP8.5 scenario } \\
\left(\Delta \text { SST patterns }{ }^{b}\right)\end{array}$ & & & \\
\hline \multirow{3}{*}{$\mathrm{HP}_{\mathrm{ALL}}\{$} & {$[\operatorname{HFYS}(\mathrm{C} 0-\mathrm{C} 3)$} & MRI-AGCM3.2H & $60 \mathrm{~km}$ & Yoshimura (YS) \\
\hline & $\mathrm{HF}_{\mathrm{ALL}}\{\mathrm{HFAS}(\mathrm{C} 0-\mathrm{C} 3)$ & MRI-AGCM3.2H & $60 \mathrm{~km}$ & Arakawa-Schubert (AS) \\
\hline & L $\operatorname{HFKF}(\mathrm{C} 0-\mathrm{C} 3)$ & MRI-AGCM3.2H & $60 \mathrm{~km}$ & Kain-Fritsch (KF) \\
\hline SPYS & SFYS (C0-C3) & MRI-AGCM3.2S & $20 \mathrm{~km}$ & Yoshimura (YS) \\
\hline
\end{tabular}

${ }^{\mathrm{a}}$ First and second characters denote the model resolution (H: $\left.60 \mathrm{~km} ; \mathrm{S}: 20 \mathrm{~km}\right)$ and the climate period (P: presentday; F: future), respectively. Third and fourth characters denote the scheme used. $\mathrm{HP}_{\mathrm{ALL}}$ and $\mathrm{HF}_{\mathrm{ALL}}$ are general term of the multi-members.

${ }^{\mathrm{b}}$ These are ensembles with four different patterns of SST change, C0-C3.

we mainly analyze precipitation over land because of the importance for impact studies. To confirm the fundamental simulation ability as a GCM, global precipitation is also evaluated. The assessment of the geographical distribution of precipitation is performed using the skill scores proposed by Taylor (2001). The score $S$ is defined as

$$
S=\frac{4(1+R)}{\left(\sigma+\sigma^{-1}\right)^{2}\left(1+R_{0}\right)}
$$

where $R$ is the spatial correlation coefficient between reference observation and simulation and $\sigma$ is the standard deviation of the simulation spatially normalized by the observation. The maximum correlation attainable $R_{0}$ is assumed to be 1 following Kusunoki (2017). We evaluated the simulations of the present-day precipitation averaged over 20 years on each native grid spacing of MRI-AGCM3.2H/S and also the simulations with MRI-AGCM3.2S interpolated onto the spacing of MRI-AGCM3.2H. Future change was estimated on the native grid spacing of each model without the spatial interpolation.

\subsection{CMIP5 multi-model ensemble}

The comparisons with the CMIP5 models used the outcomes simulated by 50 AOGCMs for the present-day climate (CMIP5 $\left.5_{\text {Present_All }}\right)$ and by 42 AOGCMs for the

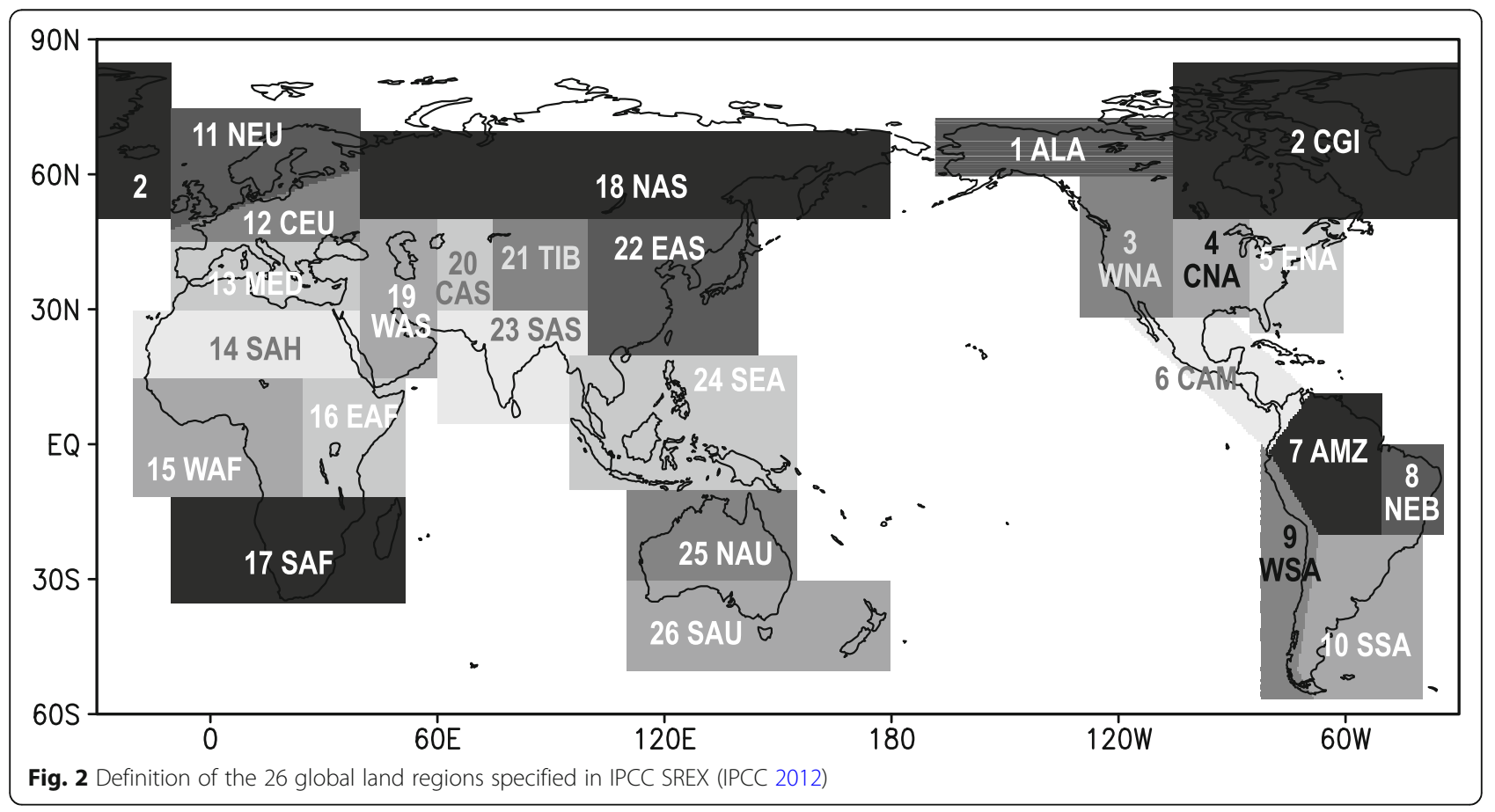


RCP8.5 future climate (CMIP5 $5_{\text {RCP8.5_All }}$ ) (Taylor et al. 2012). One ensemble member run for each model was used. Annual and seasonal mean precipitation over the same period as the MRI-AGCM3.2 dataset were computed from monthly mean data with the original horizontal resolution of each model. We then interpolated the 20-year averaged values onto the MRI-AGCM3.2H grid. The annual mean temperature used as the scaling of future precipitation change was also interpolated onto the MRI-AGCM3.2H grid for the 20-year averaged values. The models are listed in the Supplementary (Table S1).

In addition to the full ensemble of all model members, the following subsets of high performance models were produced: the subsets with high Taylor's skill scores for global precipitation $\left(\mathrm{CMIP}_{\mathrm{GhighS}}\right)$ and for regional land precipitation $\left(\mathrm{CMIP}_{\mathrm{RhighS}}\right)$, and the subsets with small mean absolute error (MAE) for global precipitation $\left(\mathrm{CMIP}_{\text {GsmallE}}\right)$. Each of the subsets has 12 members and is the same size as the set of HF members and the members of these subsets are included in both CMIP5 5 Presen-

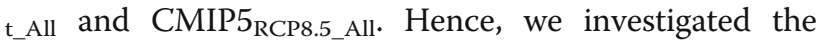
characteristics of the future projections with HF, relative to the projections with not only the CMIP5 full set but also the subsets with high performance.

\subsection{Observational products for validation}

Simulations of present-day precipitation were validated against multiple precipitation products because of the discrepancies in precipitation estimates among observational products reported by Sun et al. (2018). We used the following observational datasets. The products based on global gauge observations, which are provided over land with a grid spacing of $0.5^{\circ}$, are the Global Precipitation Climatology Centre (GPCC) full data reanalysis v.7.0 (Schneider et al. 2016), the global unified gaugebased analysis by the NOAA Climate Prediction Center (CPC) v.1.0 (Xie et al. 2010), the Climatic Research Unit Timeseries (CRU TS) v.4.03 (Harris et al. 2014), and NOAA's precipitation reconstruction over Land (PRECL) v.1.0 (Chen et al. 2002). Products that are estimated mainly from satellite data are the CPC Merged Analysis of Precipitation (CMAP; Xie and Arkin 1997), the Global Precipitation Climatology Project 1 degree daily (GPCP-1DD) v.1.2 (Huffman et al. 2001) and the Multi-Source Weighted-Ensemble Precipitation (MSWEP) v2.1 (Beck et al. 2019). The CMAP, GPCP-1DD, and MSWEP products are available over the full global surface with horizontal resolutions of $2.5^{\circ}, 1.0^{\circ}$, and $0.1^{\circ}$, respectively. All products cover the global land area for the period of interest (1984-2003, 20 years), except GPCP-1DD (1997-2014, 18 years).

The MSWEP product is provided at high resolution and covers the whole of our target period and thus was adopted as the reference dataset for the validation. MSWEP has precipitation estimates generally lying toward the mean of those from other datasets (Fig. 6 in Sun et al. 2018). The observations were interpolated onto the MRIAGCM3.2H grid. When evaluating Taylor's score and the model bias in the present-day precipitation by SP without spatial interpolation, the MSWEP precipitation was interpolated onto the MRI-AGCM3.2S grid.

\section{Results}

\subsection{Evaluation of the performance of the present-day} simulations

3.1.1 Global distribution of the simulations of present-day precipitation

Figure 3 shows the global distribution of present-day $\mathrm{P}_{\mathrm{ANN}}$ derived from observations and the bias in the model simulation. Compared with the mean of CMIP5 $5_{\text {Present_All }}$ with a maximum bias of more than 1\% (Fig. 3f), MRIAGCM3.2 simulates $\mathrm{P}_{\mathrm{ANN}}$ with a bias of less than $0.5 \%$ over most areas from the Tibetan Plateau through East Asia and Australia (Fig. 3b-e). The three members of HPs, $\mathrm{HP}_{\mathrm{ALL}}$, have a similar pattern of bias in the global land precipitation (Fig. 3c-e). Differences in the horizontal resolution between HPYS and SPYS are not largely responsible for the global distribution of the bias (Fig. 3b, e). Each member of MRI-AGCM3.2 simulates more precipitation in the Pacific intertropical convergence zone than the observations, as pointed out by Kusunoki (2017), and also over the Indian Ocean with different patterns for the three members. An overestimate of $\mathrm{P}_{\mathrm{ANN}}$ is notable over the central North Pacific and the western tropical Pacific, which is not seen or is small in the mean of CMIP5 $5_{\text {Presen- }}$ t_All. Additionally, there is a large difference in northern South America where MRI-AGCM3.2 overestimates the precipitation and the mean of CMIP5 5 Present_All underestimates it. The spatial pattern of the bias is similar between the means of CMIP5 $5_{\text {Present_All, }} \mathrm{CMIP} 5_{\mathrm{GhighS}}$, and CMIP5 $5_{\text {Gsmalle }}$ (Fig. $\left.3 f-h\right)$.

\subsubsection{Regional performance of the simulations of present- day precipitation}

In order to evaluate how well each member reproduces land $\mathrm{P}_{\mathrm{ANN}}$ at regional scale, Taylor's skill scores and model biases in the regional mean with respect to MSWEP in each of the 26 regions shown in Fig. 2 are summarized in Figs. 4 and 5, respectively. We also consider the performance of $\mathrm{CMIP}_{\text {Ghighs }}$ (i.e., the subset exhibiting the highest 12 skill scores for global precipitation; Fig. 4) and CMIP5 $5_{\text {Rhighs (i.e., the subset for regional }}$ land precipitation; Fig. 5), as well as the performances of $\mathrm{HP}_{\text {All }}$ and CMIP5 $5_{\text {Present_All }}$. We used the skill score as the main metric to select the subsets for comparison because the difference of the pattern from the observations results in a large bias. Furthermore, corrections of the spatial pattern 


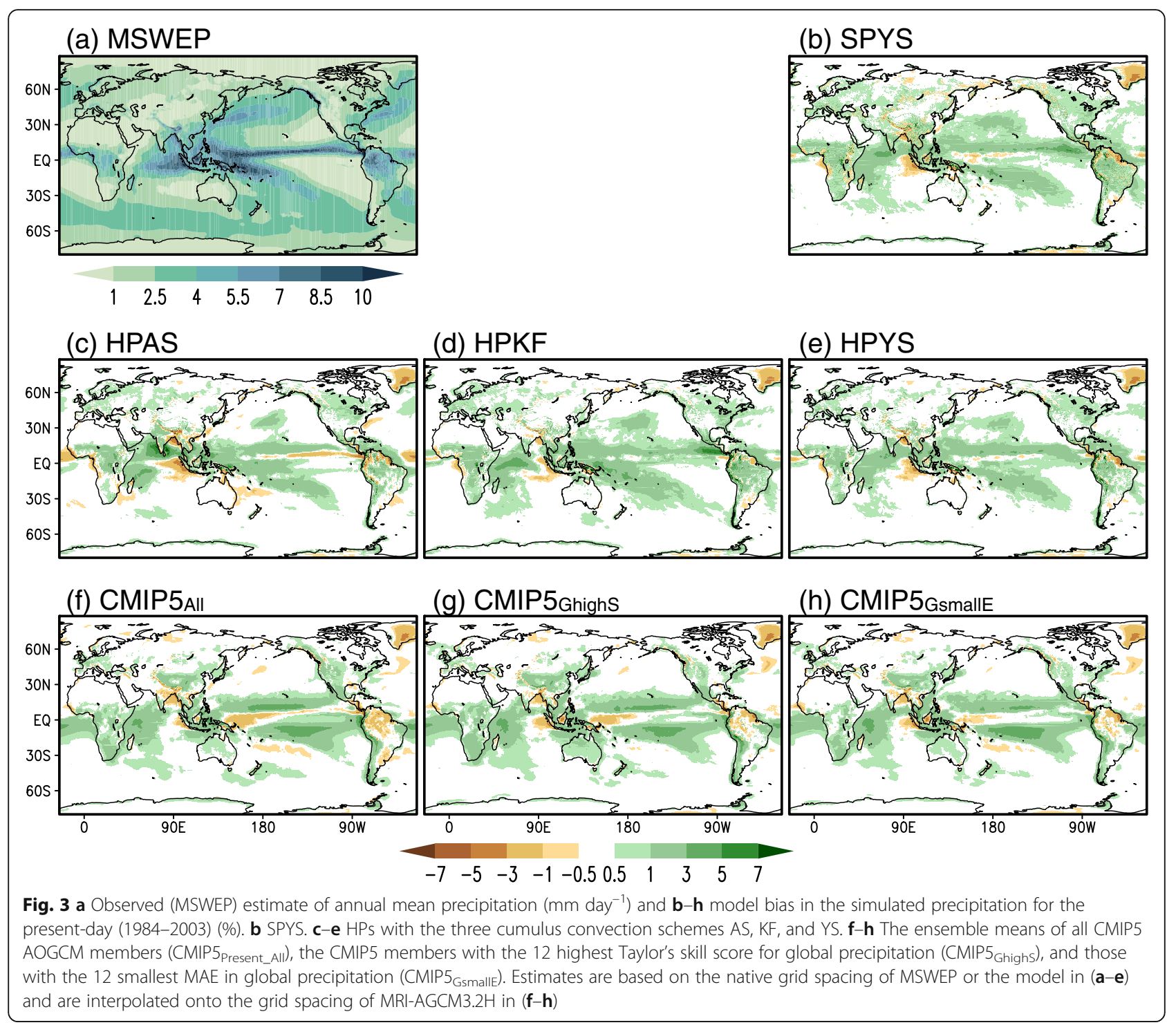

relevant to large-scale atmospheric circulations are more difficult than corrections of the bias at a grid point (e.g., Maraun 2016). The abbreviations and region numbers of individual regions used are those in Fig. 2.

The scores for all HP members exceed 0.8 in 16 regions, and in an additional five regions some HPs have a score $>0.8$, but not in wet regions of AMZ (region number 7) and SEA (24), dry regions of WSA (9) and SAH (14), and a high-latitude region of CGI (2; Fig. 4). The scores in CGI (2) are less than 0.8 but are within the discrepancy between the observations, as in the case with Europe (11-13) and Asia (18-21). There are high scores $>0.9$ in North America (3-4) and Europe $(11,13)$, in addition to TIB (21), EAS (22), and SAU (26) where the bias is small in Fig. 3. The global precipitation is also represented with a score above 0.9. Such a high score > 0.9 is approximately equal to or greater than the highest score of CMIP5 $5_{\text {Present_All }}$. The CMIP5 $5_{\text {GhighS }}$ ensemble includes members with scores lower than the 50th percentile of CMIP5 Present_All in all regions and also for global land (GLB Land in Fig. 4). That is to say, CMIP5Ghighs can represent the pattern of global $\mathrm{P}_{\mathrm{ANN}}$ realistically but does not do so well for the patterns of regional land $\mathrm{P}_{\mathrm{ANN}}$. $\mathrm{HP}_{\mathrm{All}}$, by contrast, represents both patterns closer to the observations because the average score of 0.94 over $\mathrm{HP}_{\text {All }}$ for global $\mathrm{P}_{\mathrm{ANN}}$ exceeds any scores from CMIP5 $5_{\text {present_All }}$ (GLB in Fig. 4) and all scores of $\mathrm{HP}_{\text {All }}$ for regional land $\mathrm{P}_{\mathrm{ANN}}$ are above the lowest score of CMIP5 $_{\text {GhighS, }}$ apart from the three regions WSA (9), SAS (23), and SEA (24). All HP members show a higher score than the top three scores of the 75th percentile or more in $C M I P 5_{\text {GhighS }}$, in 11 regions. Interpolating $\mathrm{P}_{\mathrm{ANN}}$ onto the MRI-AGCM3.2H grid, SPYS shows a higher score than HPYS in 12 regions. In four regions including 


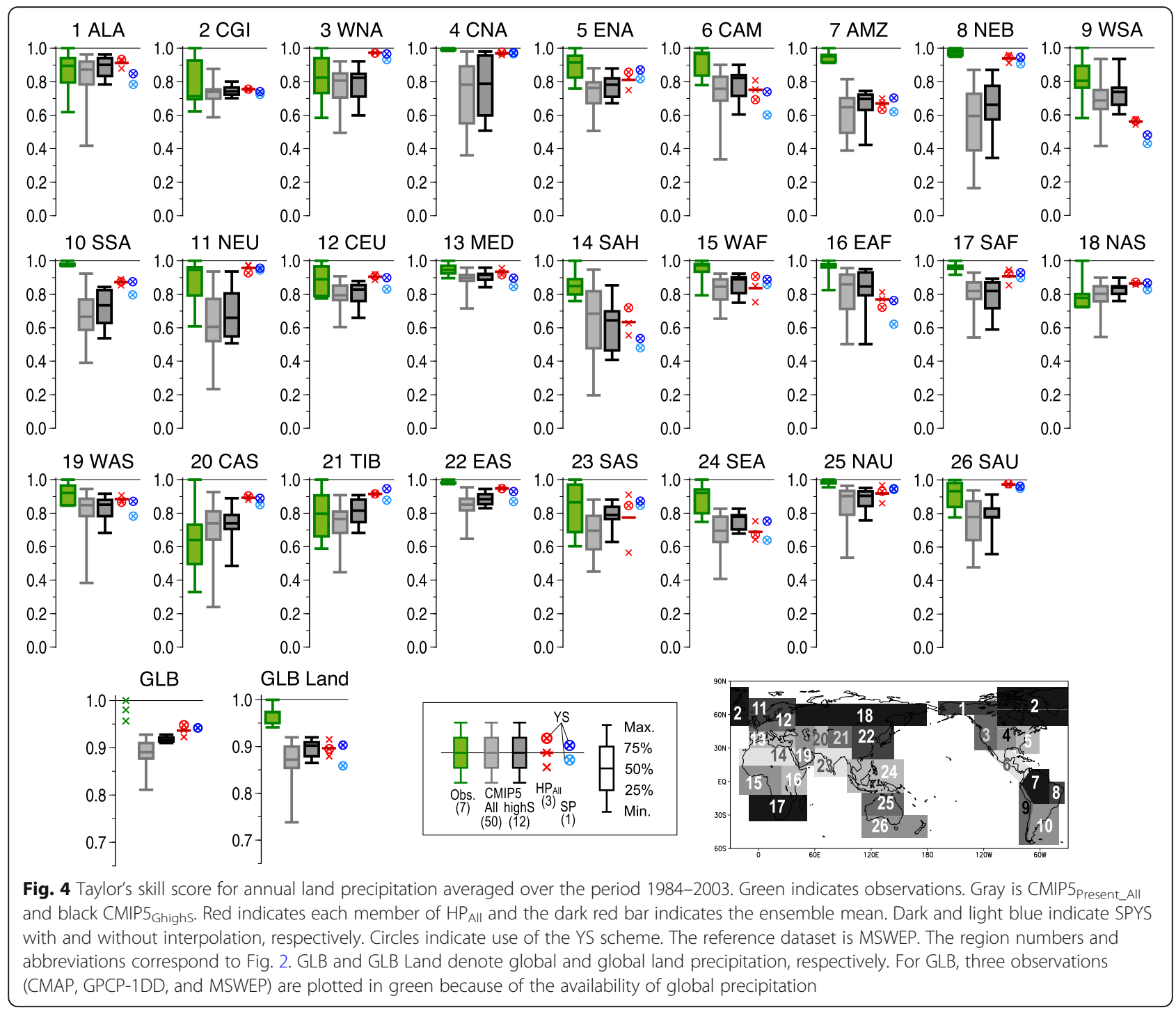

TIB (21), the score of SPYS exceeds all scores of $\mathrm{HP}_{\text {All }}$. Without the interpolation, the score decreases in all regions and the decrease is 0.05 on average over the regions.

For seasonal precipitation, $\mathrm{HP}_{\mathrm{All}}$ has a score $>0.8$ in 12 regions in JJA and 19 regions in DJF (Fig. S1). The scores in SAU (26) are greater than the highest score of CMIP5 Present_All in both the annual and the seasonal means.

Figure 5 shows that some HP members represent $\mathrm{P}_{\mathrm{ANN}}$ with a bias comparable to the discrepancies between the observations in 12 regions; e.g., South America $(7-8,10)$, South and Southeast Asia (22-24), and Australia (25-26). In the three regions CGI (2), SSA (10), and CEU (12) in particular, all biases from $\mathrm{HP}_{\mathrm{All}}$ are within the discrepancy of the observations. In CGI and CEU, all skill scores are also within the discrepancy (Fig. 4), indicating that $\mathrm{HP}_{\text {All }}$ represents precipitation quantitatively and spatially close to reality. As seen in Fig. 3, the bias in TIB (21) is more than $30 \%$ smaller in the mean of $\mathrm{HP}_{\text {All }}$ than in the 50th percentiles of CMIP5 $5_{\text {Present_All }}$ and also CMIP5 $5_{\text {RhighS. Similarly, the bias }}$ is approximately $10 \%$ smaller in EAS (22) and SAS (23) and $>25 \%$ smaller in NAU (25). All biases from $\mathrm{HP}_{\text {All }}$ are smaller than the largest bias from CMIP $5_{\text {Rhighs }}$ in all regions. Focusing on a quartile of $\mathrm{CMIP} 5_{\text {Rhighs }}$ indicating the three smallest biases, the bias is larger in $\mathrm{HP}_{\mathrm{All}}$. However, we should note that the combination of three members selected from CMIP5 $5_{\text {Rhighs }}$ varies region-byregion, whereas the same HP members are evaluated consistently in every region.

Although $\mathrm{HP}_{\mathrm{ALL}}$ simulates well the spatial pattern of global and global land precipitation relative to CMIP5 5 Present_All (Fig. 4), the members overestimate the precipitation, in particular, the global land precipitation with a bias comparable to the 75th 


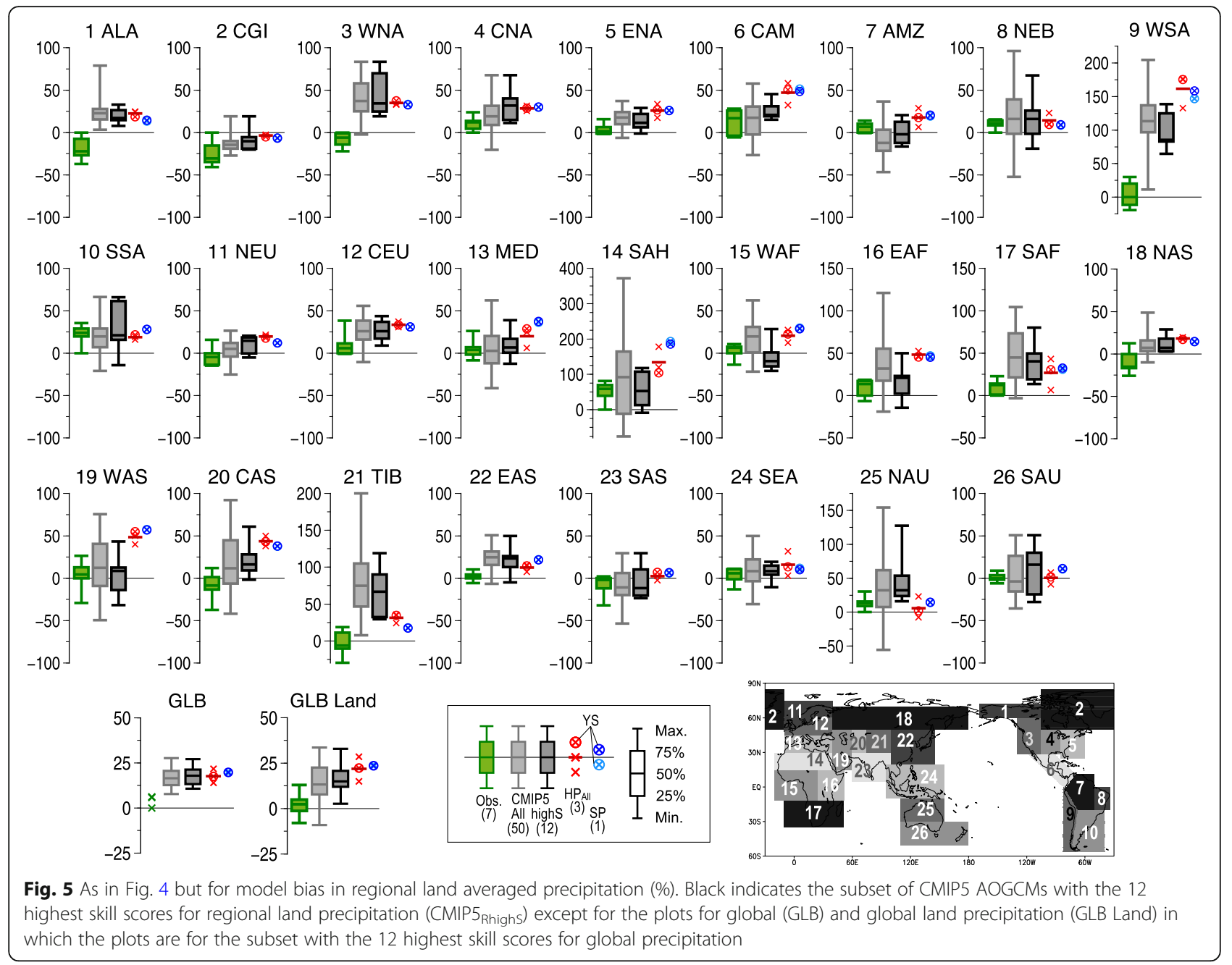

percentile of CMIP5 $5_{\text {Present_All }}$ and $\mathrm{CMIP} 5_{\text {GhighS. This }}$ is because areas of negative bias are more widely distributed in the mean of CMIP5 $5_{\text {Present All than in }}$ $\mathrm{HP}_{\mathrm{ALL}}$ (Fig. 3) and, consequently, the bias is offset

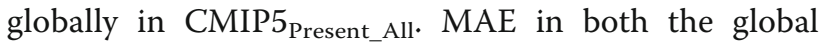
land and sea and global land precipitation from $\mathrm{HP}_{\mathrm{ALL}}$ is smaller or comparable to the smallest MAE from CMIP5 $5_{\text {Present_All }}$ (not shown).

Depending on the convection scheme used, $\mathrm{P}_{\mathrm{JJA}}$ simulated by $\mathrm{HP}_{\text {All }}$ are within the spread of observations in 17 regions and $\mathrm{P}_{\mathrm{DJF}}$ in 15 regions (Fig. S2). In CEU (12), all biases in the annual and the seasonal means are comparable to the discrepancies between observations.

SPYS simulates $\mathrm{P}_{\mathrm{ANN}}$ with less bias than HPYS in more than half the regions on the common MRIAGCM3.2H grids, and also $\mathrm{P}_{\mathrm{JJA}}$ in 10 regions and $\mathrm{P}_{\mathrm{DJF}}$ in 16 regions. In addition, the bias in $\mathrm{P}_{\mathrm{ANN}}$ from SPYS is small regardless of the convection scheme used in $\mathrm{HP}_{\mathrm{All}}$ in seven regions including TIB (21). The skill score reduces in all regions when evaluating the SPYS precipitation on the native grid (Fig. 4). On the other hand, the bias in the regional mean precipitation is almost equal in cases with and without the interpolation except for WSA (9) with the complex terrains of the Andes, where the bias reduces by $10 \%$ in the evaluation on the native grid. This implies that there may be a difference in the spatial pattern of precipitation between MSWEP and SPYS.

\subsubsection{Model rank for the performance over the regions}

To gain an overview of the performance of each model, we ranked 55 models using MAE and skill score: three of $\mathrm{HP}_{\mathrm{All}}$, the interpolated SPYS, 50 of the individual model members of CMIP5 $5_{\text {Present_All, and the MME mean }}$ of CMIP5 Present All. The rank of each model and the MME mean were computed as follows. First, in each region, each model was ranked from 1 to 55 according to its MAE or score, with rank 1 assigned to the model with the smallest MAE or the highest score. Secondly, for each model, the order/rank in each region was averaged over all the regions. A small overall rank corresponds to the model having a smaller MAE or a higher score in many regions. 


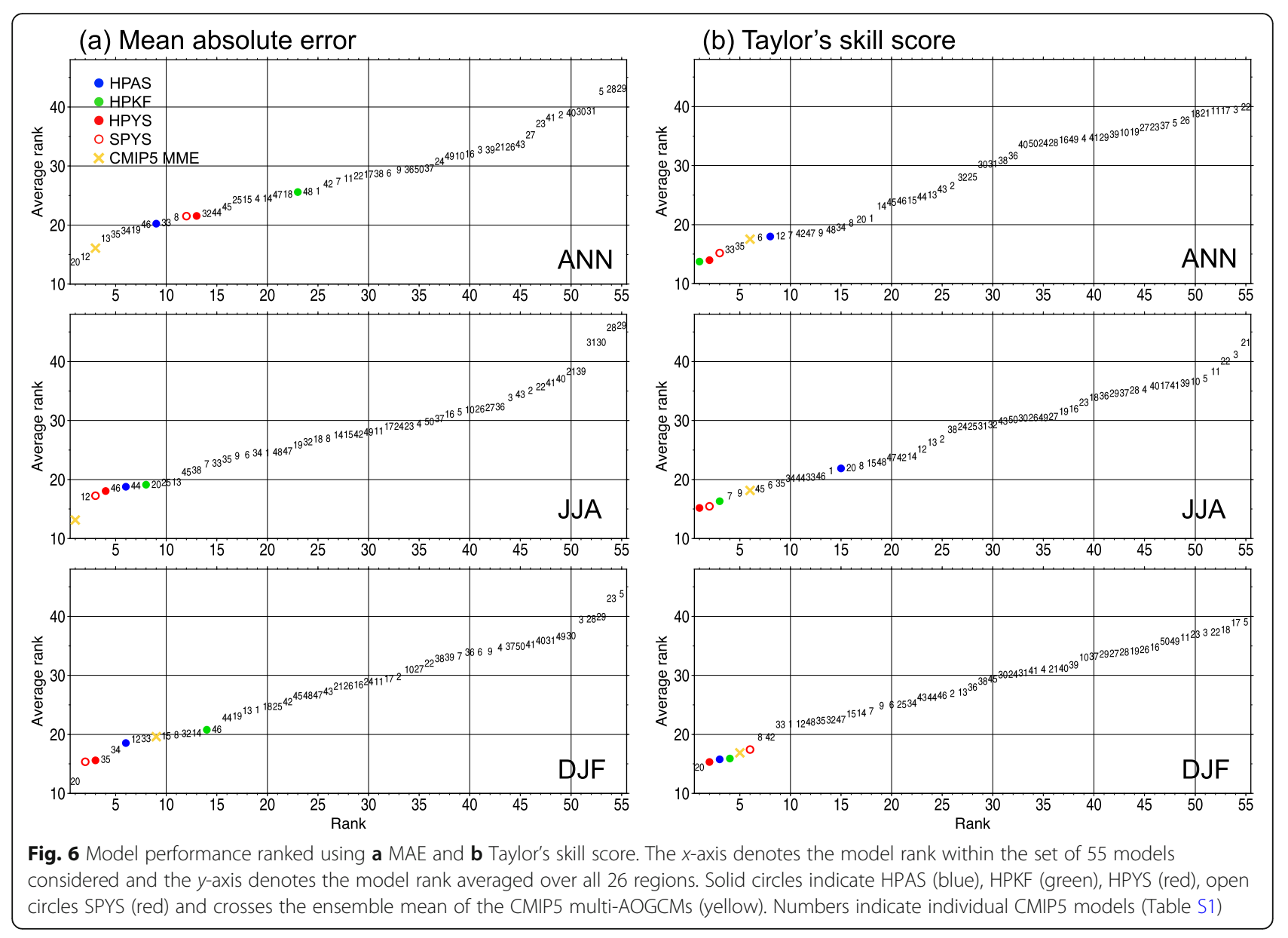

The $x$-axis in Fig. 6 denotes the rank from 1 to 55 based on the average rank and the $y$-axis denotes the rank averaged over the regions. $\mathrm{HP}_{\text {All }}$ and SPYS always rank in the top 15 models for both metrics except for MAE in $P_{\text {ANN }}$ from HPKF. In particular, HPYS and SPYS are always in the top five models for the seasonal precipitation. For the skill score, individual members of HPs and SPYS are often ranked higher than the MME mean of CMIP5 Present_All. HPKF has the best average rank of 13.7 on the score for $\mathrm{P}_{\mathrm{ANN}}$, and HPYS and SPYS follow HPKF with average ranks of 14.0 and 15.2, respectively. HPYS has the best rank on the score for $\mathrm{P}_{\mathrm{JJA}}$, followed by SPYS and HPKF. Thus, $\mathrm{HP}_{\text {All }}$ and SPYS can simulate the spatial pattern and the regional mean of the present-day precipitation close to the observations in more regions than can the CMIP5 models. The CMIP5 models change their rank depending on the metric, and their ranks are not always above those of $\mathrm{HP}_{\mathrm{All}}$. Namely, prescribing observed SST for a GCM contributes to a more realistic spatial pattern and amount of regional precipitation climatology around the globe. The order of rank is almost the same when using the AMIP-type simulations in the CMIP5 (Fig. S3), and $\mathrm{HP}_{\mathrm{All}}$ is ranked around the MME mean of the AMIP simulations, especially for the skill score.

\subsection{Future change projection for the RCP8.5 scenario 3.2.1 Global comparison of the uncertainty in future precipitation change}

Figure $7 \mathrm{a}-\mathrm{d}$ illustrates the future change of $\mathrm{P}_{\mathrm{ANN}}$ averaged over the projections by the $\mathrm{HF}_{\mathrm{All}}$ ensemble and the MMEs of CMIP5 $5_{\text {RCP8.5_All, CMIP5 }}$ GhighS, and

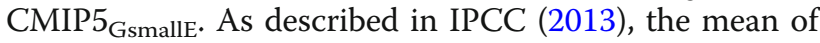
CMIP5 $5_{\text {RCP8.5_All }}$ projects an increase of global land $\mathrm{P}_{\mathrm{ANN}}$ at the $90 \%$ confidence level in most regions of the middle- and high-latitude Northern Hemisphere and a decrease around the Mediterranean (Fig. 7b). The regions with a significant change extend farther in $\mathrm{HF}_{\mathrm{All}}$ than in

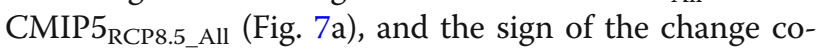
incides with the sign given by CMIP5 $5_{\text {RCP } 8.5 \text { All in most }}$ regions (Fig. 7e). In Australia and northern South America, the mean of $\mathrm{HF}_{\text {All }}$ projects an increase at the $90 \%$ confidence level while that of CMIP $5_{\mathrm{RCP} 8.5 \text { Anll }}$ projects an insignificant decrease (Fig. 7e). Figure 7 h shows that the mean of $\mathrm{HF}_{\text {All }}$ projects a noticeably wetter climate over the land than the mean of CMIP5 $5_{\mathrm{RCP} 8.5 \_ \text {All }}$, 


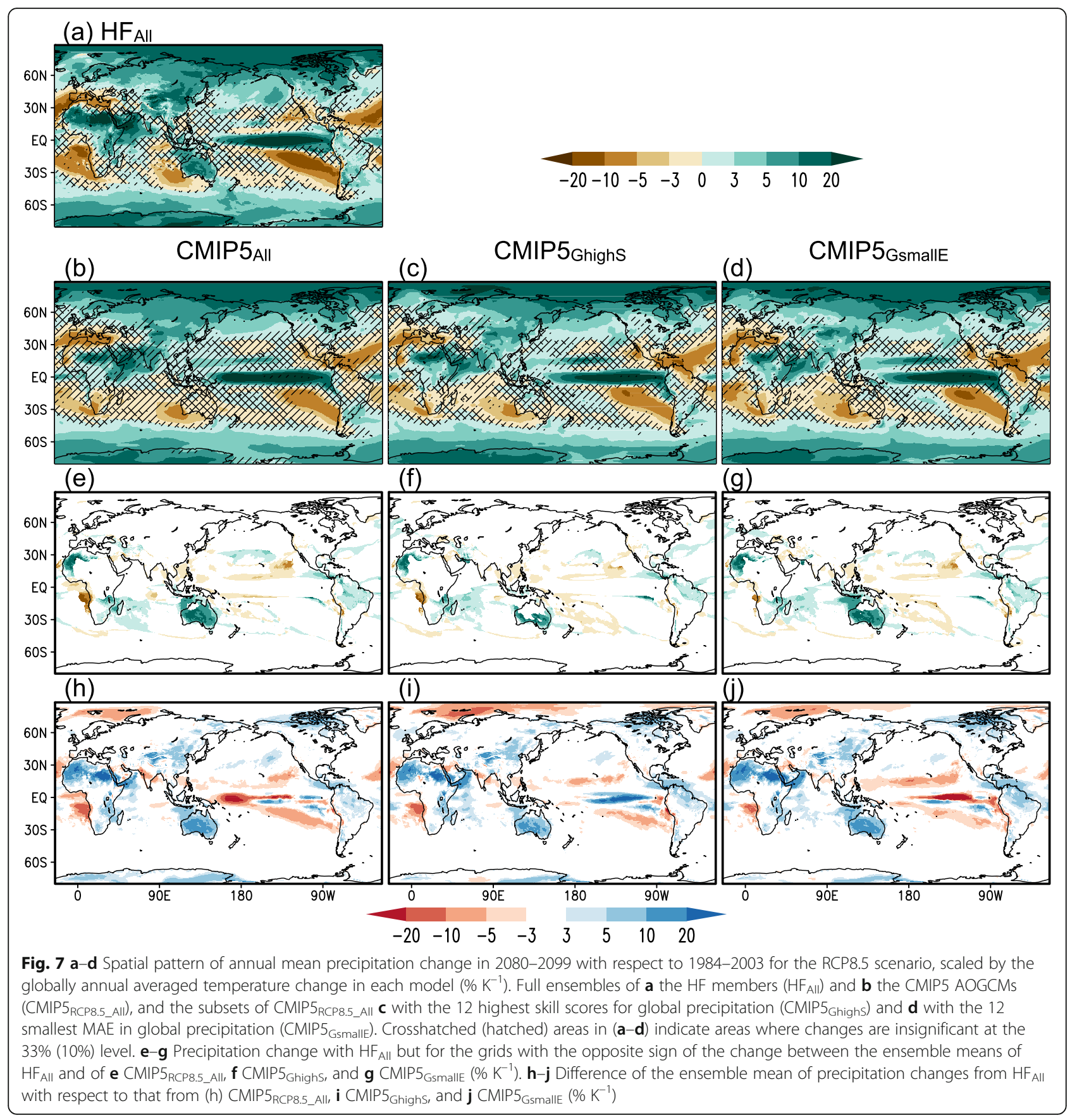

especially from the Tibetan Plateau to East Asia, over northern South America, and the dry regions of Australia and the Sahara. The projections from the full ensemble of the CMIP5 models and its subsets are similar over the land even when the models are selected by their performance on present-day precipitation (Fig. 7c, $d, i, j)$. Although the precipitation change over the ocean is beyond the scope of this study, we note that the change over the tropical Pacific is different in the means of the CMIP5 $5_{\mathrm{RCP} 8.5 \text { All }}$ and the subsets. $\mathrm{HF}_{\text {All }}$ projects a precipitation change with an El Niño-like pattern on the ensemble mean, relative to the CMIP5 $5_{R C P 8.5}$ All projections (Fig. 7h). The pattern, however, is not always detected in the comparison with the high-performing subset projections (Fig. 7i, j). The changes in $\mathrm{P}_{\mathrm{JJA}}$ and $\mathrm{P}_{\mathrm{DJF}}$ show a similar pattern over the tropical Pacific (Figs. S4 and S5).

In order to identify features of the uncertainty in future precipitation changes from $\mathrm{HF}_{\mathrm{All}}$, we explored how the uncertainty spread of $\mathrm{HF}_{\mathrm{All}}$ compares with that from the CMIP5 $5_{\text {RCP } 8.5}$ models. Previous studies assessed the uncertainty from subsets of ensemble members using 
the degree to which the maximum-minimum range of uncertainty from all ensemble members is covered by the range from the subset (McSweeney et al. 2015; Karmalkar 2018; Ito et al. 2020a). Following this methodology and expressing precipitation changes for ensemble $\mathrm{E}$ as $\Delta \mathrm{P}(\mathrm{E})$, we computed the fraction of the maximumminimum range of $\Delta \mathrm{P}\left(\mathrm{HF}_{\mathrm{All}}\right)$ to the range of $\Delta \mathrm{P}\left(\mathrm{E}^{\prime}\right)$, and refer to this as a fraction of the relative range (FR). Here, we used three ensembles as the ensemble E': all 42 members of CMIP5 $5_{\text {RCP8.5 All }}$, and the 12 members of each of $\mathrm{CMIP} 5_{\text {Ghighs }}$ and CMIP5 $5_{\text {GsmallE}}$.

The value of FR for $\mathrm{HF}_{\text {All }}$ relative to CMIP5 RCP8.5_All, $_{\text {, }}$ $F_{\text {All }}$, exceeds 0.7 around North America, southern Africa, East Asia, and Australia (Fig. 8a). Grid cells where $\mathrm{FR}_{\mathrm{All}}$ lies between 0.7 and 1.3 (i.e., the spread of $\Delta \mathrm{P}_{\mathrm{ANN}}\left(\mathrm{HF}_{\mathrm{All}}\right)$ is within $\pm 30 \%$ of the spread of $\Delta \mathrm{P}_{\mathrm{ANN}}$

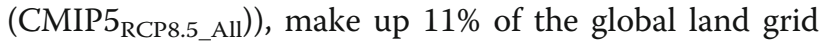
cells, and grid cells with values between 0.5 and 1.5 make up $35 \%$. As for $\mathrm{CMIP} 5_{\text {Ghighs }}$ and $\mathrm{CMIP} 5_{\text {GsmallE}}$, the percentage of the grid cells with FR within 0.7-1.3 $(0.5-1.5)$ increases up to approximately $45 \%$ (75\%) (Fig. $8 \mathrm{~b}, \mathrm{c})$. Therefore, selecting the high-performance CMIP5 models to represent the present-day precipitation more than doubles the area where the uncertainty ranges of $\mathrm{HF}_{\mathrm{All}}$ and the selected CMIP5 models are close. The fraction from the uncertainty of CMIP5 $5_{\text {Ghighs }}, \mathrm{FR}_{\mathrm{GhighS}}$, exceeds 0.7 over most land areas. A similar spatial pattern is seen in the fraction from $\mathrm{CMIP} 5_{\text {Gsmalle }}, \mathrm{FR}_{\mathrm{Gsmall}}$. Of the 12 members in each of $\mathrm{CMIP} 5_{\text {Ghighs }}$ and CMIP5 $5_{\text {GsmallE, }}$, three members of CMIP $5_{\text {Ghighs }}$ are not in CMIP5 Gsmalle. Thus, the three members make their own patterns, e.g., Australia and South America around the tropical Pacific where a different pattern of $\Delta \mathrm{P}_{\mathrm{ANN}}$ appears (Fig. 7i, j).

The tendency for a closer spread between $\mathrm{HF}_{\mathrm{All}}$ and the high-performing subsets of the CMIP5 models is detected in the seasonal precipitation change (Fig. S6). As with the annual precipitation change, for the seasonal precipitation change, the percentage of the grid cells with $\mathrm{FR}_{\text {Ghighs }}$ and $\mathrm{FR}_{\text {GsmallE }}$ within 0.5-1.5 increases to approximately $70 \%$ of all land grid cells from $40 \%$ in $\mathrm{FR}_{\mathrm{All}}$.

\subsubsection{Uncertainty in the projected change of regional mean precipitation}

The projected future change of regional mean $\mathrm{P}_{\mathrm{ANN}}$ over land is shown in Fig. 9. Here, we analyze the projections by the MMEs of CMIP5 $5_{\text {GhighS }}$ and CMIP5 $5_{\text {RhighS }}$, together with the $\mathrm{HF}_{\mathrm{All}}$ ensemble and the CMIP5 $5_{\mathrm{RCP} 8.5}$ _All $\mathrm{MME}$. Additionally, considering the effects of model resolution, the future changes projected with SF are also considered, which were computed from the regional mean on the native grid of MRI-AGCM3.2S.
There is a wide spread in the projections $\triangle \mathrm{P}\left(\mathrm{CMIP} 5_{\mathrm{RC}}\right.$ P8.5_All) in low-latitude regions and a narrower spread in the middle- and high-latitude regions, as shown in IPCC (2013) with respect to both land and sea areas. The uncertainty from $\Delta \mathrm{P}\left(\mathrm{HF}_{\mathrm{All}}\right)$ of the annual and seasonal precipitation presents a similar picture (Fig. S7). This may be due to the difference in the main precipitation systems; i.e., the major systems are sub-grid scale (produced by cumulus convection schemes) at low latitudes and grid scale at middle and high latitudes.

The maximum-minimum uncertainty range from $\mathrm{HF}_{\text {All }}$ partly overlaps all the range from CMIP5 $5_{\mathrm{RCP} 8.5 \text { _All }}$, $\mathrm{CMIP} 5_{\text {GhighS }}$, and $\mathrm{CMIP} 5_{\text {RhighS }}$ except for CMIP5 $5_{\text {RhighS }}$ in CGI (2). The range from $\mathrm{HF}_{\mathrm{All}}$ is 0.4 of the range from $C M I P 5_{R C P 8.5}$ All on average over all 26 regions; the fraction increases to $0.8(0.73)$ of the range from CMIP5Ghighs $\left(C M I P 5_{\text {Rhighs }}\right)$. In terms of the future change in the global average, specifically global land precipitation, the spread of the projections with $\mathrm{HF}_{\mathrm{All}}$ is equal to 0.74 of the spread from CMIP5 $5_{\mathrm{RCP} 8.5 \text { All }}$ and to 0.95 of that from $\mathrm{CMIP} 5_{\mathrm{Ghighs}}$. Thus, the future change projected with $\mathrm{HF}_{\mathrm{All}}$ roughly has an uncertainty very close to the uncertainty in the projections with the high-performing CMIP5 models, as described above. In the individual areas, the projections with $\mathrm{HF}_{\mathrm{All}}$ have a wider spread than the range from $C M I P 5_{\text {Ghighs }}$ and $C M I P 5_{\text {Rhighs }}$ in SAF (17) and AMZ (7), and a comparable spread in NEB (8), WAS (19), EAS (22), SEA (24), and SAU (26). On the other hand, there is a relatively small spread of the $\mathrm{HF}_{\text {All }}$ projections in NAS (18) and TIB (21). The projections with the SF ensemble lie within the uncertainty from $\mathrm{HF}_{\mathrm{All}}$ in most regions. Given that the SF ensemble is the ensemble of only four patterns of SST change, the spread is small but the individual regional pattern of spread resembles the spread from $\mathrm{HF}_{\text {All }}$.

Over the Tibetan Plateau and East Asia, where a significant increase is projected by the ensemble means of

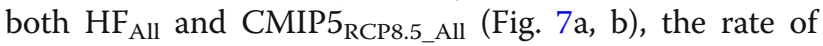
increase is $0.5-2 \%$ larger in $\mathrm{HF}_{\text {All }}$ on average over TIB (21) and EAS (22). The rate in TIB is an additional 1\% larger in the mean of the SF ensemble than that of $\mathrm{HF}_{\mathrm{All}}$, which is a marked difference compared with other regions. The projected future change has the opposite sign of future change between the 50th percentiles of $\Delta \mathrm{P}\left(\mathrm{HF}_{\mathrm{All}}\right)$ and $\triangle \mathrm{P}\left(\mathrm{CMIP} 5_{\mathrm{RCP} 8.5}\right.$ _All $)$ in six regions around the tropical South Pacific: Central and South America (6 -9) and Australia (25-26). In particular, in CAM (6) and NEB (8), more than three $\mathrm{HF}_{\mathrm{All}}$ members project an increase and different three members project a decrease so that the future change is insignificant. On the other hand, although there is a large uncertainty in the projections with not only CMIP5 $5_{\text {RCP8.5_All }}$ but also CMIP5Ghighs and CMIP5 $5_{\text {RhighS }}$, more than $75 \%$ of $\mathrm{HF}_{\text {All }}$ project an increase in AMZ (7), NAU (25), and SAU (26) and a 

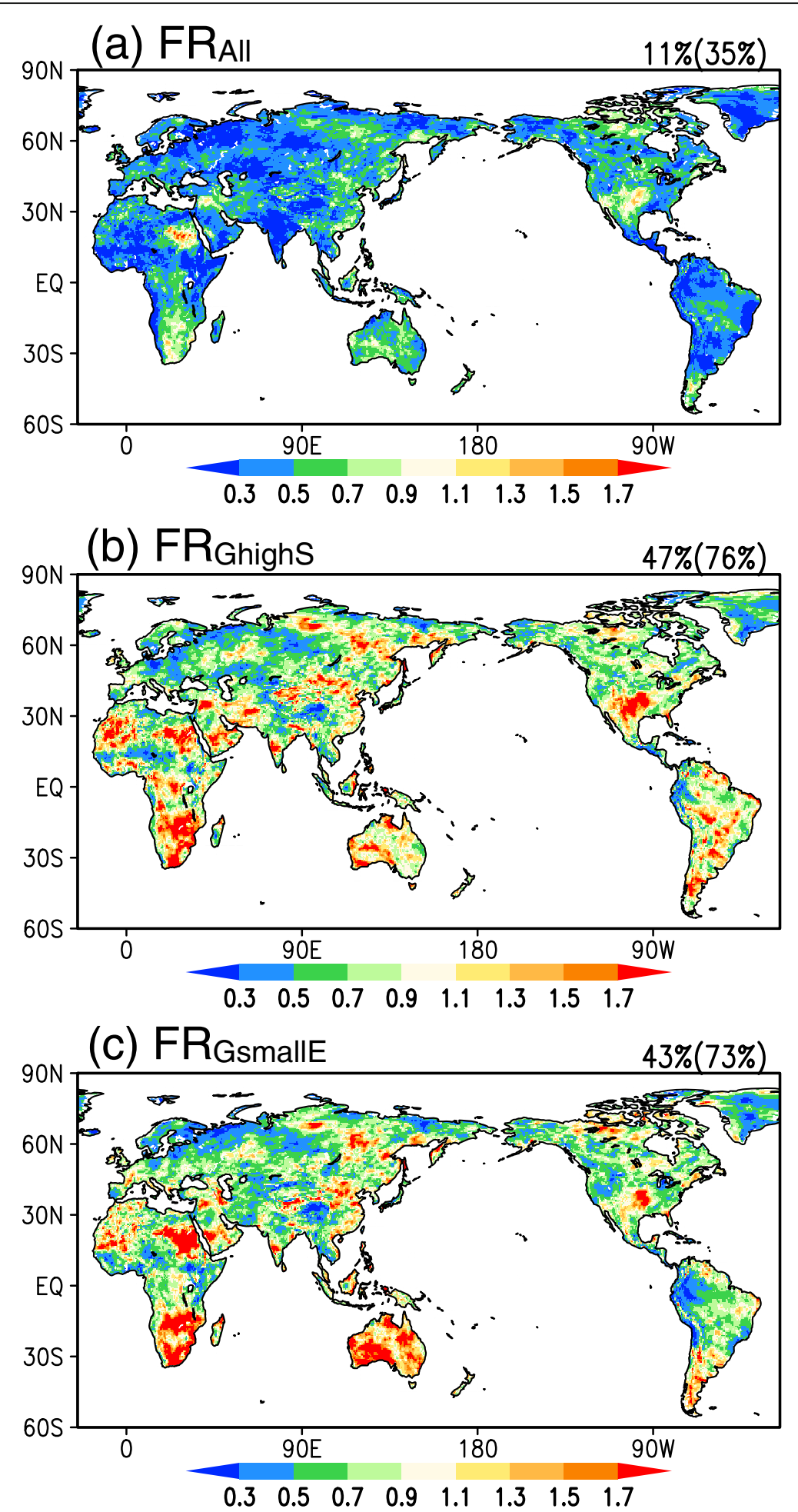

Fig. 8 Fraction of relative range of the uncertainty from $\mathrm{HF}_{\text {All }}$ to the range from a CMIP5 $5_{R C P 8.5}$ All, $\mathbf{b} C M I P 5_{\text {Ghighs, }}$ and $\mathbf{c} C M I P 5_{G s m a l l E}$. The value at the top right of each panel denotes the percentage of grid cells with FR between 0.7 and 1.3 in the global land, and the value in the parentheses denotes the percentage between 0.5 and 1.5 


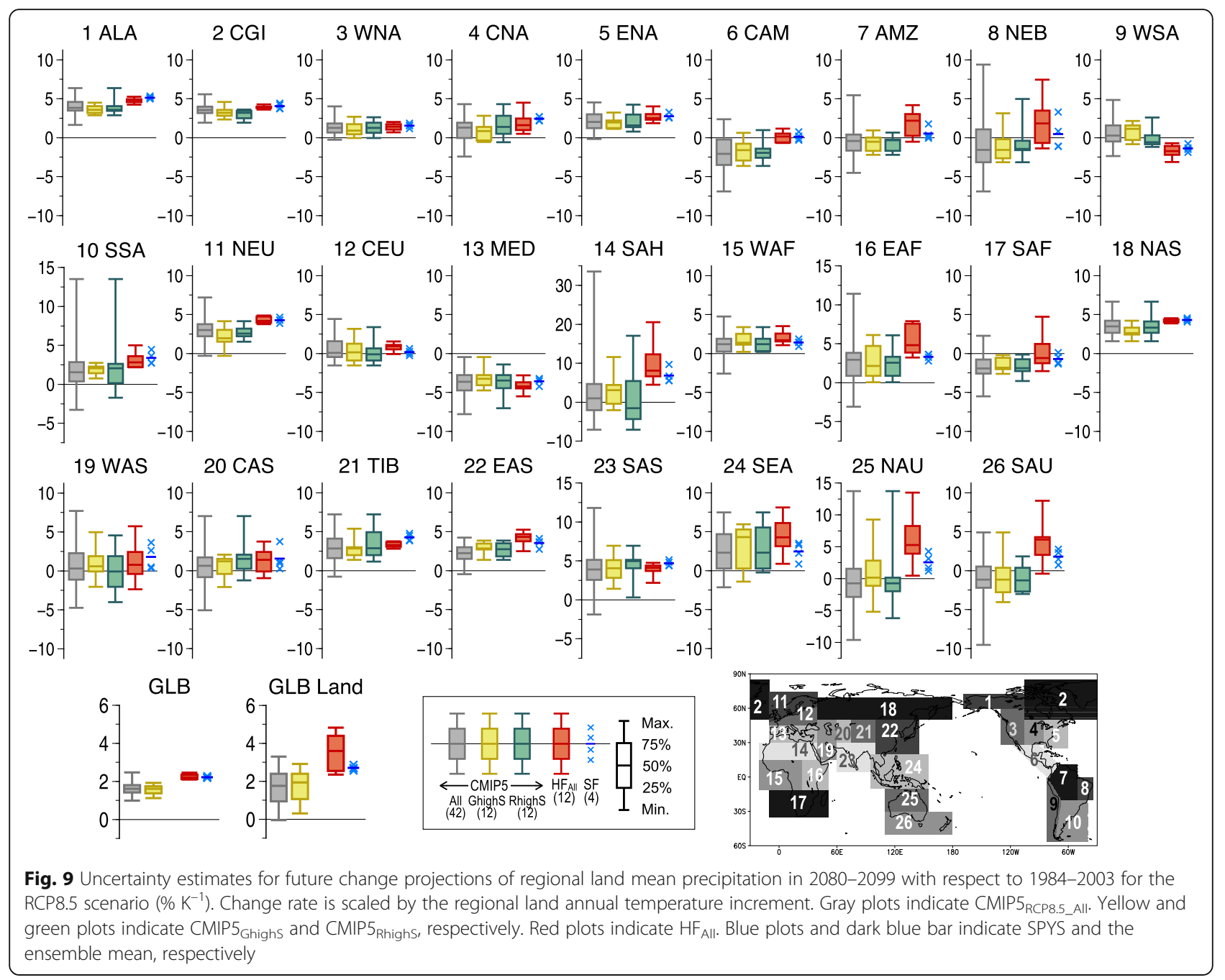

decrease in WSA (9). In particular, all members of $\mathrm{HF}_{\text {All }}$ project the opposite sign to the 50th percentiles of $\triangle \mathrm{P}\left(\mathrm{CMIP}_{\mathrm{RCP} 8.5}\right.$ All $)$ in WSA and NAU. In NAU, the 50th percentile of $\triangle \mathrm{P}\left(\mathrm{HF}_{\mathrm{All}}\right)$ is $5.3 \%$ while that of $\triangle \mathrm{P}\left(\mathrm{CMIP}_{\mathrm{RCP} 8.5 \_ \text {All }}\right)$ is $-0.7 \%$. Of the six regions with opposite signs in different ensembles, the mean of $\mathrm{HP}_{\mathrm{All}}$ has a score $>0.8$ in NEB (8) and Australia (Fig. 4) and a bias comparable to the discrepancies between observations in AMZ (7), NEB (8), and Australia (Fig. 5). This suggests that forcing with the observed SST reduces the SST bias in $\mathrm{HP}_{\text {All }}$ compared with the CMIP5 coupled simulations, and consequently $\mathrm{HP}_{\text {All }}$ performs well in representing the present-day precipitation. On the other hand, with regard to future simulations, the differences between the atmosphere-only model and the coupled model could cause the opposite sign in the future precipitation changes in the regions. A relatively large positive precipitation change in $\mathrm{HF}_{\mathrm{All}}$ is consistent with Kitoh and Arakawa (1999), who have demonstrated that the lack of SST and cloud-radiation feedback in
AGCMs brings about an overestimate of precipitation in warm-SST regions.

For the global mean, $\mathrm{HF}_{\mathrm{All}}$ projects a wetter climate

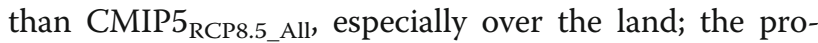
jections with more than half the members of $\mathrm{HF}_{\mathrm{All}}$ exceed the maximum changes of CMIP5 $5_{\text {RCP8.5_All }}$ and

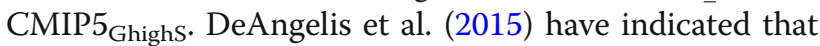
CMIP5 models that underestimate the sensitivity of shortwave absorption to an increase in atmospheric water vapor tend to overestimate the precipitation increase. From their results, the CMIP5 model developed at MRI shows a lower sensitivity of shortwave absorption than the other CMIP5 models. The radiation scheme in that model is almost the same as the scheme used in MRI-AGCM3.2 for computing the sensitivity. Thus, the sensitivity could to some extent contribute to the greater increase of the precipitation by $\mathrm{HF}_{\text {All }}$ than by CMIP5 $5_{\mathrm{RCP} 8.5 \_ \text {All }}$.

Similar to $\mathrm{P}_{\mathrm{ANN}}$, the projections of $\mathrm{HF}_{\mathrm{All}}$ spread over 0.35 and 0.46 of the maximum-minimum uncertainty range from $\Delta \mathrm{P}_{J J A}\left(C M I P 5_{\mathrm{RCP} 85 \_A l l}\right)$ and $\Delta \mathrm{P}_{\mathrm{DJF}}\left(\mathrm{CMIP} 5_{\mathrm{RCP} 8.5 \_A l l}\right)$ on 
average over all 26 regions, respectively (Fig. S7). The fraction increases to 0.78 and 0.96 of the range from $\Delta \mathrm{P}_{J J A}(C$ $\left.\mathrm{MIP}_{\mathrm{GhighS}}\right)$ and $\Delta \mathrm{P}_{\mathrm{DJF}}\left(\mathrm{CMIP} 5_{\mathrm{GhighS}}\right)$, respectively.

\section{Discussion}

\subsection{Contribution of cumulus schemes and SST forcing to} the uncertainty

The uncertainty from $\mathrm{HF}_{\mathrm{All}}$ is estimated from the future precipitation changes by 12 ensemble members corresponding to combinations of three different cumulus convection schemes and four SST change patterns. In order to discuss the sources of uncertainty in the $\mathrm{HF}_{\mathrm{All}}$ projections, we created two subsets, one with different convection schemes but the same CO SST-change pattern $\left(\mathrm{HF}_{\mathrm{Conv}}\right.$; three members) and the other with the same YS scheme but different SST change patterns ( $\mathrm{HF}_{\mathrm{SST}}$; four members). The FR values were then estimated for the maximum-minimum uncertainty range from the projections with $\mathrm{HF}_{\text {Conv }}$ and $\mathrm{HF}_{\mathrm{SST}}$ relative to the range with $\mathrm{HF}_{\mathrm{All}}\left(\mathrm{FR}_{\mathrm{Conv}}\right.$ and $\mathrm{FR}_{\mathrm{SST}}$, respectively). $\mathrm{FR}_{\text {Conv }}\left(\mathrm{FR}_{\mathrm{SST}}\right)$ denotes the ratio of $\mathrm{HF}_{\mathrm{Conv}}\left(\mathrm{HF}_{\mathrm{SST}}\right)$ covering the uncertainty from $\mathrm{HF}_{\text {All }}$.

Figure 10 shows global distributions of $\mathrm{FR}_{\mathrm{Conv}}$ and $\mathrm{FR}_{\mathrm{SST}}$. The area where either $\mathrm{HF}_{\text {Conv }}$ or $\mathrm{HF}_{\mathrm{SST}}$ captures over 0.6 of the uncertainty from $\mathrm{HF}_{\mathrm{All}}$ is only approximately $40 \%$ of the global land, implying that the ensemble consisting of both multiple SST patterns and multiple convection schemes is needed to cover most of the uncertainty from the high-performing CMIP5 models. $\mathrm{FR}_{\text {Conv }}$ is larger than $\mathrm{FR}_{\mathrm{SST}}$ in Africa and northern South America (Fig. 10a). On the other hand, a relatively large $\mathrm{FR}_{\mathrm{SST}}$ appears around Australia and Siberia (Fig. 10b). Around Asia, Endo et al. (2012) have assessed the contribution of each factor to the uncertainty by analysis of variance on the same MRI-AGCM3.2H dataset. Their results indicate that the uncertainty in $\Delta \mathrm{P}_{\mathrm{ANN}}$, as well as in $\Delta \mathrm{P}_{\mathrm{JJA}}$ and $\Delta \mathrm{P}_{\mathrm{DJF}}$, is mainly caused by differences in the cumulus convection schemes in South and Southeast Asia, which is consistent with the relatively large $\mathrm{FR}_{\text {Conv }}$ seen in Fig. 10a.

To investigate the atmospheric fields leading to the spreads of the projections of $\Delta \mathrm{P}_{\mathrm{ANN}}$, Fig. 11 shows the standard deviation in future change for three atmospheric circulation variables: sea level pressure $(\triangle \mathrm{SLP})$, temperature at $850 \mathrm{hPa}(\Delta \mathrm{T} 850)$, and geopotential height at $500 \mathrm{hPa}(\Delta \mathrm{Z} 500)$. Because of the common SST change pattern, the deviation in $\Delta \mathrm{T} 850$ from $\mathrm{HF}_{\mathrm{Conv}}$ is globally small except for the western part of the tropical Pacific (Fig. 11b). On the other hand, $\mathrm{HF}_{\text {Conv }}$ shows a relatively large deviation in $\Delta \mathrm{Z} 500$ over the tropical and subtropical regions of $30^{\circ} \mathrm{S}-30^{\circ} \mathrm{N}$ (Fig. 11c). That is to say, the response of $\Delta \mathrm{Z} 500$ over the regions depends on the cumulus convection scheme, which may relate to the difference in the precipitation changes between the different cumulus schemes. Therefore, $\mathrm{FR}_{\mathrm{Conv}}$ is large around Africa and northern South America over $30^{\circ} \mathrm{S}$ $-30^{\circ} \mathrm{N}$. The dependence of $\Delta \mathrm{Z} 500$ on the schemes over $30^{\circ} \mathrm{S}-30^{\circ} \mathrm{N}$ is seen regardless of the patterns of SST change; the KF (AS) scheme gives a more positive (negative) anomaly in $\Delta \mathrm{Z} 500$ than the YS scheme (Fig. S8a).

$\mathrm{HF}_{\text {SST }}$ shows a roughly similar distribution of the deviation in $\triangle T 850$ to that in the SST change (Figs. 1a and 11e). Around Australia where $F_{S S T}$ is large, $\triangle$ SLP from $\mathrm{HF}_{\mathrm{SST}}$ shows a large deviation (Fig. 11d). The difference of $\triangle$ SLP between members with different SST change patterns responds to the prescribed patterns of El Niño/ La Niña-like SST change over the Pacific (Fig. S8b). The atmospheric response to the El Niño/Southern Oscillation (ENSO) expands over Australia and brings about a relatively large uncertainty in the precipitation changes with $\mathrm{HF}_{\mathrm{SST}}$.

With reference to Mizuta et al. (2014), we divided CMIP5 models into three clusters to obtain future change patterns of SST and sea ice $(\mathrm{C} 1-\mathrm{C} 3)$ for future

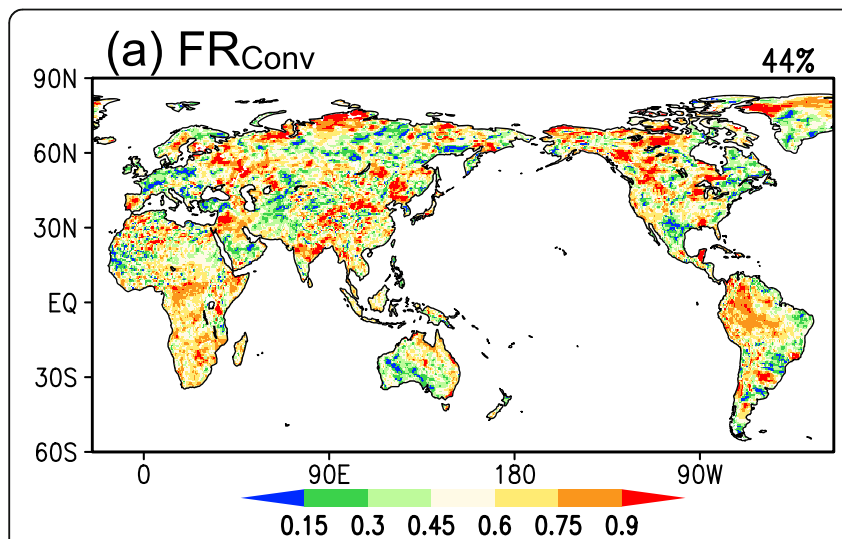

(b) FRSST

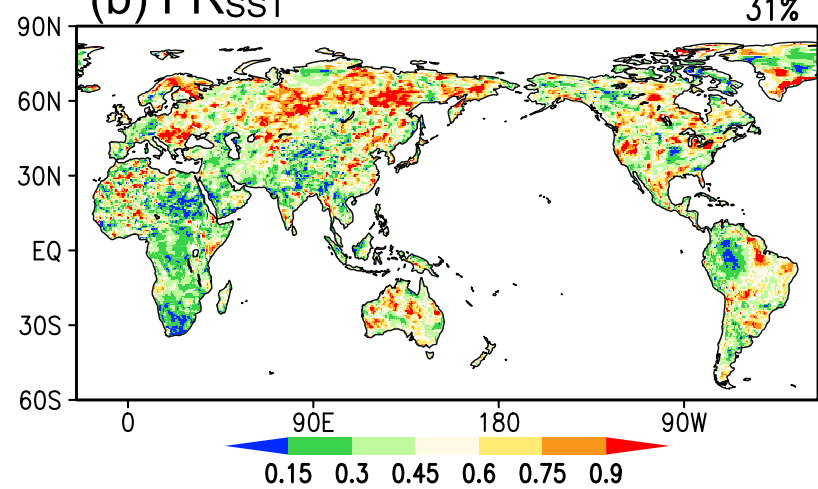

Fig. 10 As in Fig. 8 but for the fraction relative to the uncertainty from $\mathrm{HF}_{\text {All }}$ for a the three members of $\mathrm{HF}_{\text {All }}$ with different convection schemes $\left(\mathrm{HF}_{\text {Conv }}\right)$ and $\mathbf{b}$ the four members with different patterns of SST change $\left(\mathrm{HF}_{\mathrm{SST}}\right)$. The value at the top right of each panel denotes the percentage of grid cells with FR over 0.6 in the global land 


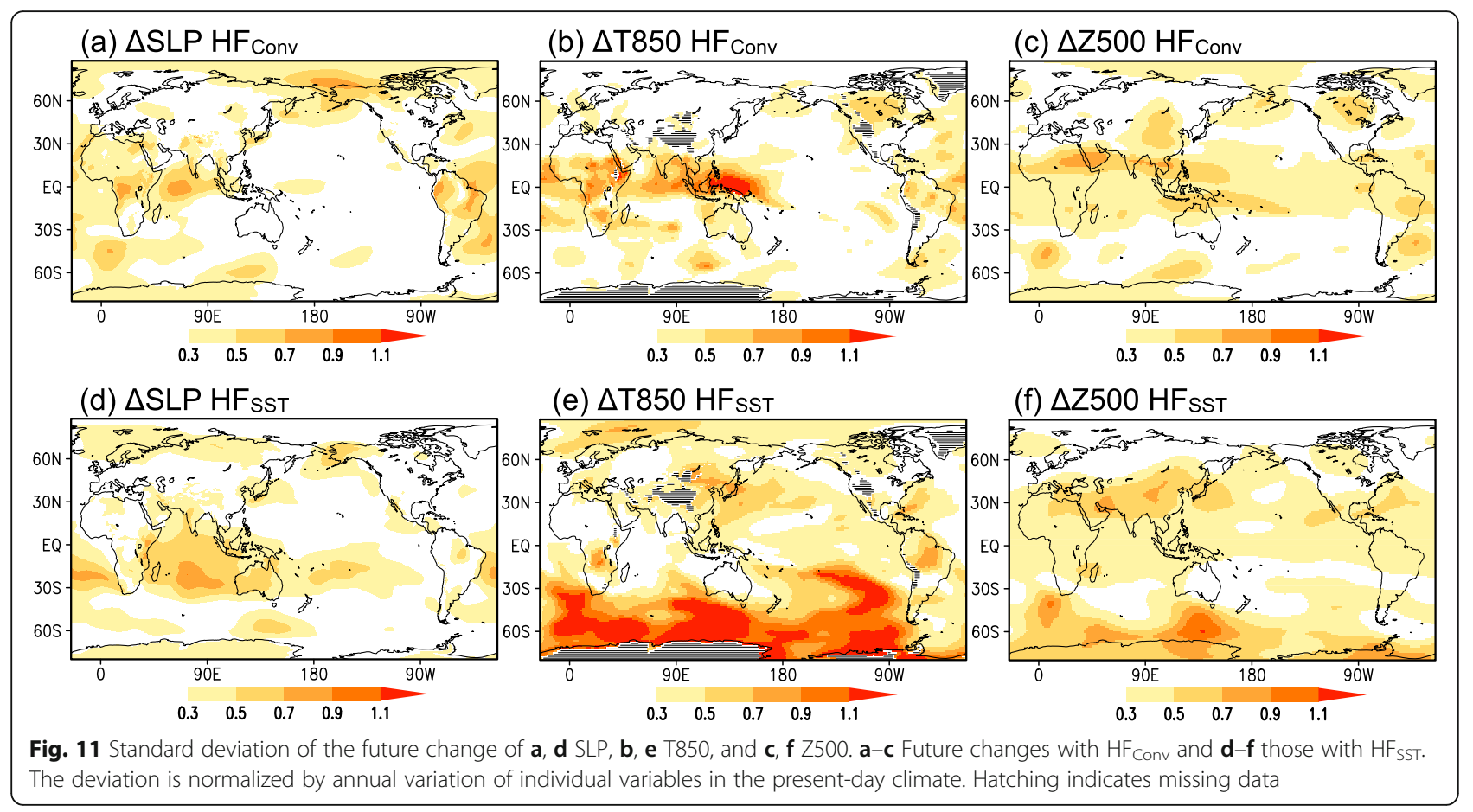

climate simulations with MRI-AGCM3.2. The $\triangle$ SLP were then averaged over the models in each cluster and over all models to derive four spatial patterns of $\triangle$ SLP corresponding to the pattern from each member of $\mathrm{HF}_{\mathrm{SST}}$. The spatial pattern of the deviation in $\triangle \mathrm{SLP}$ from the clusters of the CMIP5 models (Fig. S9) resembles the pattern from the $\mathrm{HF}_{\mathrm{SST}}$ projections over the latitudinal band of $0^{\circ}-30^{\circ} \mathrm{S}$ (Fig. 11d). That is, there is a similarity in the atmospheric response to the SST change between the ensembles of MRIAGCM3.2 and the CMIP5 models, implying that the difference in the precipitation change around Australia between the ensembles arises from a quantitative difference in the response to a similar change of atmospheric circulation. The uncertainty could also be associated with differences in the convection schemes, especially in the northern regions of Australia at latitudes north of $30^{\circ} \mathrm{S}$ (Fig. 11c). These might lead to large uncertainty in NAU (25 in Fig. 9).

A large $\mathrm{FR}_{\mathrm{SST}}$ around Siberia is partially affected by teleconnections such as the Pacific-North America patterns in response to the same ENSO-like change (Horel and Wallace 1981), as is also the case around North America and Asia (Fig. 11d). Urabe and Maeda (2014) and Imada et al. (2017) pointed out the seasonal variations in the appearance of the teleconnection pattern around Asia. Future study is required focusing on the effects of the seasonal change of the teleconnection pattern.

\subsection{Enhanced model resolution}

In order to examine the impact of the horizontal resolution of models on the simulations of $\mathrm{P}_{\mathrm{ANN}}$, we summarized the relationship between the following four indices and the complexity in topography in the 26 regions: the extent of the change in skill score and model bias in the regional mean from HPYS to SPYS (Fig. 12a, b), the difference in the ensemble mean of $\Delta \mathrm{P}_{\mathrm{ANN}}$ (Fig. 12c), and the ratio of the maximum-minimum uncertainty range from $\Delta \mathrm{P}_{\mathrm{ANN}}$ projected by SFYS to the range from $\mathrm{HF}_{\mathrm{SST}}$ (Fig. 12d). The indices were estimated on the native grid of each model. The future change is the projected change in the regional mean. The ensemble of SFYS and HF $_{\text {SST }}$ consists of the four members with the same YS scheme and different four patterns of SST change. The complexity in topography is defined as the standard deviation of the altitude represented by MRIAGCM3.2S.

The impact of the enhanced horizontal resolution is a significant decrease in model bias. The relationship between the complexity and the decrease in the bias is statistically significant at the $99 \%$ confidence level. The difference in the ensemble means of future changes is positively correlated with the complexity, although the relationship is insignificant. This is also the case for the uncertainty range. Consequently, simulations by the high-resolution model may project a greater future precipitation increase around complex terrain regions, with a reduction of the model bias in 


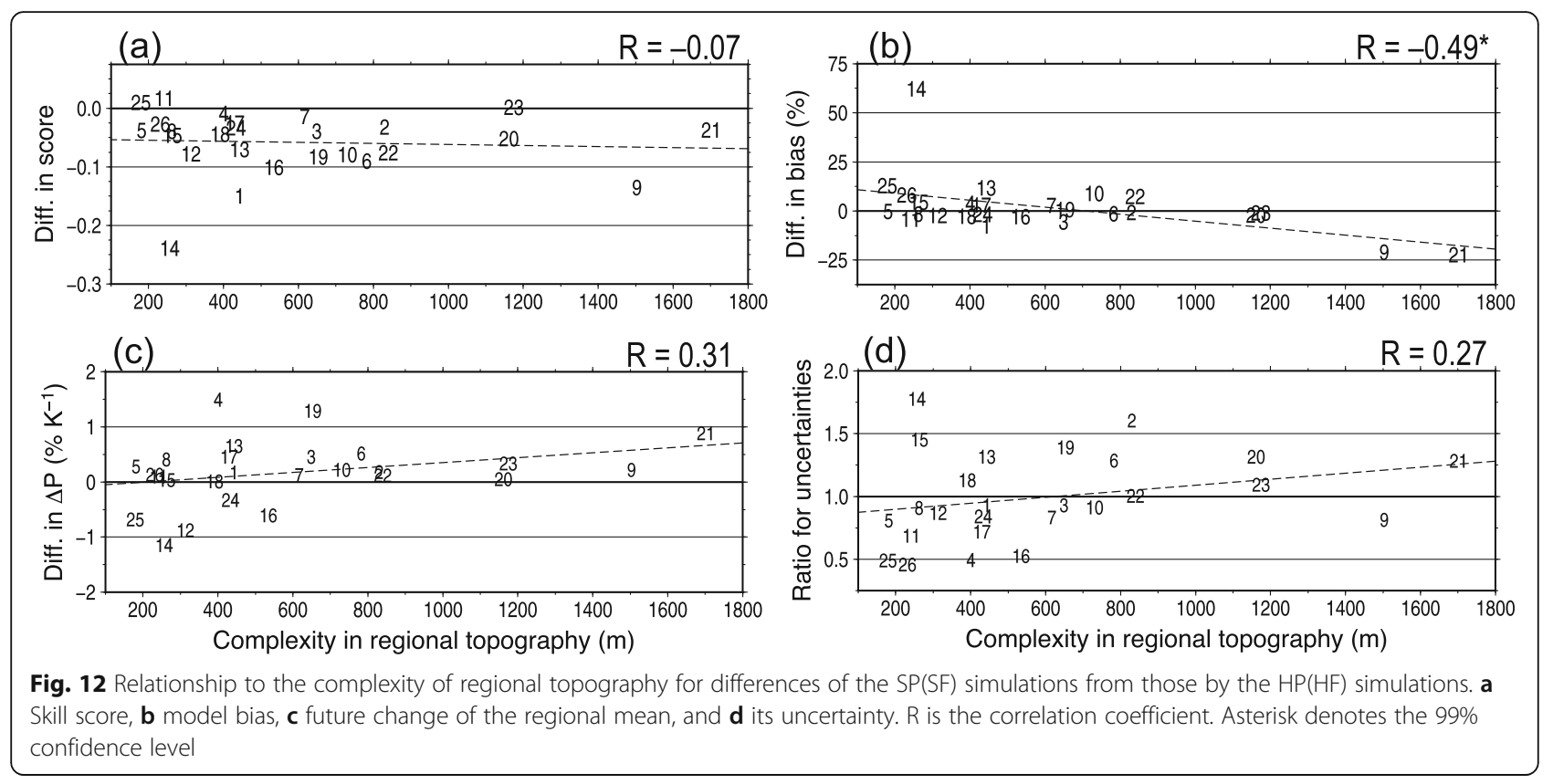

the present-day precipitation. Furthermore, there is a possibility that the uncertainty in the future projections is greater in regions with more complex topography.

As seen in Fig. 4, the skill score is smaller across all regions in SPYS than in HPYS except for NEU (11) and NAU (25), regardless of the complexity. It seems that the high-resolution model cannot simulate the precipitation pattern better than the lowresolution one. However, Fig. 4 shows a large discrepancy in the score for the observations, with a value of 0.4 in TIB (21) and WSA (9), regions with high complexity in the topography. Thus, we cannot conclude that the high-resolution model performs poorly in representing the spatial pattern. Further validation is needed using observations with a resolution of a few tens of kilometers that is high enough to evaluate the simulations with MRIAGCM3.2S.

Note that the difference in the simulations between various model resolutions derives from not only the represented topography but also the precipitation systems themselves that the model is able to resolve. According to Ito et al. (2020b), focusing on the areas around Japan that are included in EAS (22), the projection of the regional precipitation changes when considering the effect of typhoons that low-resolution models cannot represent.

The impact of the model resolution is more effective in the simulations of extreme indices; e.g., a seasonal maximum of 1-day precipitation total. Similar to the need for projections of average climate change, this is important for the impact assessment of climate change.

\section{Summary}

We have shown that the simulations by MRIAGCM3.2 reproduce well the present-day precipitation climatology in regions around the globe and that the signs of future changes at the 50th percentile are identical to the CMIP5 multi-AOGCM ensemble in almost all regions. The projections of future precipitation change spread over roughly 0.4 of the uncertainty range from the full ensemble of the CMIP5 AOGCMs and, furthermore, 0.8 of the range from the high-performing CMIP5 AOGCMs.

The precipitation climatology simulated by MRIAGCM3.2 is closer to observations at both global and regional scales in terms of the spatial pattern and amount. Compared with the means of the CMIP5 ensemble and the high-performing CMIP5 ensembles, the model bias is reduced by approximately $20 \%$ for regional averages from the Tibetan Plateau through East Asia and Australia. Overall, MRI-AGCM3.2 has a skill score of more than 0.8 in almost all the 26 global land regions and the model bias for at least one of the cumulus convection schemes is within the discrepancy between observations in about half of the regions.

When ranking the score and absolute error for the simulated land precipitation in individual regions, MRI-AGCM3.2 ranks in the top 15 of all 55 model runs including all 50 of the CMIP5 ensemble members and their mean (except for HPKF for the error in the annual precipitation). MRI-AGCM3.2 is ranked almost equal to or higher than the CMIP5 ensemble mean for the skill scores in the annual and the 
seasonal mean and the biases in the seasonal mean. Therefore, MRI-AGCM3.2 can represent the spatial pattern and the regional mean of precipitation realistically in more regions than the CMIP5 ensemble members.

The spatial distribution of projected change in global precipitation of the ensemble means of MRI-AGCM3.2 and the CMIP5 models is similar. MRI-AGCM3.2 projects a greater increase of regional-mean precipitation than the CMIP5 ensemble mean, from 0.5 to $2 \%$ greater around the Tibetan Plateau and East Asia and even more in Australia where the model bias is small in MRIAGCM3.2. This is also the case for the comparison with the high-performing CMIP5 ensemble.

The sign of future change for annual precipitation is the same at the 50th percentile in 20 out of 26 regions and the opposite in the other six regions around the tropical South Pacific; e.g., Australia and South America. In these six regions, the skill score for the present-day precipitation exceeds 0.8 in three regions and the bias is comparable to the difference between the observations in four regions. Thus, we expect that the use of the prescribed SST in the MRI-AGCM3.2 simulations results in a small bias in the present-day regional precipitation, while the difference between models with or without atmosphereocean coupling has an influence on the future projections. Although the relationship between the ability to reproduce the present-day climate and the ability to provide reliable future predictions is still unclear (e.g., Smith and Chandler 2010; He and Soden 2016), high performance in simulations of the present-day precipitation by MRI-AGCM3.2 is an important metric for assessing the accuracy of the model itself.

The uncertainty in the MRI-AGCM3.2 projections partly overlaps the maximum-minimum range of the uncertainty in the projections with the CMIP5 model ensemble in all regions. By considering the uncertainty range from MRI-AGCM3.2 as a fraction of the range from the CMIP5 models, the percentage of grid cells with the fraction between 0.7 and 1.3 (between 0.5 and 1.5$)$ is approximately $10 \%(35 \%)$. The percentage increases to $45 \%$ (75\%) when the comparison is made with respect to the CMIP5 models that perform well for precipitation simulations in the present-day, suggesting that the uncertainty is closer to that from the high-performing CMIP5 ensemble than that from the full ensemble. Also, regarding the uncertainty in future changes in the regional mean precipitation, the range from the MRI-AGCM3.2 projections increases from 0.4 of the range from all the CMIP5 models to around 0.8 of that from the high-performing CMIP5 models on average over individual regions. That is to say, the MRI-AGCM3.2 dataset provides the regional information on the projections with an uncertainty comparable to the uncertainty from the highperforming CMIP5 models around the globe, together with well-represented precipitation in the present-day climate.

The difference of projections by MRI-AGCM3.2 relative to the CMIP5 model ensemble may be caused partly by the difference between an atmospheric model and the atmosphere-ocean coupled models of the CMIP5 AOGCMs, as seen in regions around the tropical Pacific. MRI has developed a new model system that assimilates observed SST in such coupled models, which enables the evaluation of atmosphere-ocean coupled effects; e.g., SST and cloud-radiation feedback (Kitoh and Arakawa 1999). Comparisons of projections from such a model will facilitate investigation of the causes of the differences identified here.

The characteristics of the precipitation climatology summarized in this study are highly useful not only for studies of global and regional climatology using the MRI-AGCM3.2 dataset but also for decisions on adaptation strategies. As already discussed on the CORDEX phase 1 in Ito et al. (2020a), the use of a GCM dataset to discuss regional climate changes requires a fundamental evaluation of the projections by the GCM as the regional scale, as we have done here. This will be applied, for example, with HighResMIP and CORDEX phase 2.

\section{Supplementary Information}

The online version contains supplementary material available at https://doi. org/10.1186/s40645-020-00394-4.

\footnotetext{
Additional file 1: Table S1. CMIP5 models used in this study. (Retrieved from https://cmip.IInl.gov/cmip5/availability.html on May 23, 2019). Figure S1. As in Fig. 4 but for (a) JJA mean precipitation and (b) DJF mean precipitation. Figure S2. As in Fig. 5 but for (a) JJA mean precipitation and (b) DJF mean precipitation (\%). Figure S3. As in Fig. 6 but for the AMIP-type simulations instead of the CMIP5 simulations. Black number corresponds to the number in the list of models at the bottom. Gray number denotes the rank in Fig. 6 only for the model of which the name coincides with that in Table S1. Figure S4. As in Fig. 7 but for JJA mean precipitation $\left(\% \mathrm{~K}^{-1}\right)$. White in $(\mathrm{a}-\mathrm{d})$ and hatching in $(\mathrm{e}-\mathrm{j})$ indicate the grid cells where the models simulate no precipitation in the presentday climate. Figure S5. As in Fig. 7 but for DJF mean precipitation (\% K $\left.{ }^{1}\right)$. White in $(a-d)$ and hatching in $(e-j)$ indicate the grid cells where the models simulate no precipitation in the present-day climate. Figure S6. As in Fig. 8 but for (a) JJA mean precipitation and (b) DJF mean precipitation. Hatching indicates the grid cells where the models simulate no precipitation in the present-day climate. Figure S7. As in Fig. 9 but for (a) JJA mean precipitation and (b) DJF mean precipitation $\left(\% \mathrm{~K}^{-1}\right)$. Figure S8. Future change anomaly for each of $12 \mathrm{HF}$ ensemble members from their mean. (a) Future change of geopotential height at $500 \mathrm{hPa}$ and (b) that of sea level pressure. Members on each row are the member with the same SST-change pattern for the future climate simulation. Members on each column are the member with the same cumulus convection scheme. The anomaly is normalized by the annual variation of individual variables in the present-day climate. Crosshatching (Hatching) indicates the 99\% (90\%) confidence level. Figure S9. Standard deviation in future changes of sea level pressure using three clusters of the CMIP5 AOGCMs
} 
and all of them, which were created to obtain future change patterns of sea surface temperature and sea ice for the MRI-AGCM3.2 simulations by Mizuta et al. (2014). The deviation is normalized by the annual variation in the present-day climate averaged over the CMIP5 models in each cluster. (see text for details).

\section{Abbreviations}

GCM: General circulation model; MRI-AGCM3.2: Meteorological Research Institute atmospheric GCM version 3.2; CMIP5: Coupled Model Intercomparison Project phase 5; AOGCM: Atmosphere-ocean coupled GCM; RCM: Regional climate model; IPCC AR5: The Fifth Assessment Report of the Intergovernmental Panel on Climate Change; CORDEX: The Coordinated Regional Downscaling Experiment; HighResMIP: The High Resolution Mode Intercomparison Project; SST: Sea surface temperature; KF: Kain-Fritsch; AS: Arakawa-Schubert; YS: Yoshimura; HadISST: Hadley Centre's sea ice and sea surface temperature dataset; RCP: Representative concentration pathway; JJA: June-August; DJF: December-February; IPCC SREX: The IPCC Special Report on Managing the Risks of Extreme Events and Disasters to Advance Climate Change Adaptation; MAE: Mean absolute error; GPCC: Global Precipitation Climatology Centre; CPC: Climate Prediction Center; CRU TS: Climatic Research Unit Timeseries; PRECL: Precipitation Reconstruction Over Land; CMAP: CPC Merged Analysis of Precipitation; GPCP-1DD: Global Precipitation Climatology Project 1 degree daily; MSWEP: Multi-source weighted-ensemble precipitation; MME: Multi-model ensemble; FR: Fractional of a relative range; ENSO: El Niño/Southern Oscillation

\section{Acknowledgements}

The authors would like to acknowledge Dr. H. Endo, Dr. H. Kawai, and Dr. Y. Imada of the Meteorological Research Institute, Japan meteorological Agency, and Dr. H. Shiogama of the National Institute for Environmental Studies for their constructive comments and useful suggestions. In addition, the authors would like to appreciate the anonymous reviewers who provided insightful comments on the earlier version of this paper.

\section{Authors' contributions}

All authors conceptualized the study and participated in the discussion. RI analyzed the data, prepared and revised the manuscript. All authors approved the final manuscript.

\section{Funding}

This work was supported by the Integrated Research Program for Advancing Climate Models (TOUGOU) Grant Number JPMXD0717935561 from the Ministry of Education, Culture, Sports, Science and Technology (MEXT), Japan.

\section{Availability of data and materials}

CMIP5 multimodel dataset is publicly available via the website of Earth System Grid Federation (http://pcmdi9.IInl.gov/). Observation products are publicly available online via each website: GPCC (https://www.dwd.de/EN/ ourservices/gpcc/gpcc.html), CPC (https://ftp.cpc.ncep.noaa.gov/precip/CPC_ UNI_PRCP/), CRU (https://crudata.uea.ac.uk/cru/data/hrg/cru_ts_4.01/), PRECL (http://ftp.cpc.ncep.noaa.gov/precip/50yr/gauge/), CMAP (https://ftp-cpc. ncep.noaa.gov/precip/cmap), GPCP (ftp://meso.gsfc.nasa.gov/pub/gpcp-v2.2/ ), MSWEP (http://www.gloh2o.org). The availability of the dataset created by MRI-AGCM3.2 is limited due to the property of TOUGOU program, MEXT, Japan, but are available from the corresponding author on reasonable request or under the condition of collaborative research.

\section{Competing interests}

The authors declare that they have no competing interest.

\section{Received: 27 February 2020 Accepted: 24 November 2020}

\section{Published online: 14 December 2020}

\section{References}

Beck HE, Wood EF, Pan M, Fisher CK, Miralles DG, van Dijk AlJM, McVicar TR, Adler RF (2019) MSWEP V2 global 3-hourly $0.1^{\circ}$ precipitation: methodology and quantitative assessment. Bull Amer Meteor Soc 100:473-500. https://doi.org/ 10.1175/BAMS-D-17-0138.1
Chen M, Xie P, Janowiak JE, Arkin PA (2002) Global land precipitation: a 50-yr monthly analysis based on gauge observations. J Hydrometeor 3:249-266. https://doi.org/10.1175/1525-7541(2002)003<0249:GLPAYM>2.0.CO;2

DeAngelis AM, Qu X, Zelinka MD, Hall A (2015) An observational radiative constraint on hydrologic cycle intensification. Nature 528:249-253. https://doi.org/10.1038/nature15770

Endo $H$, Kitoh A, Mizuta R, Ishii M (2017) Future changes in precipitation extremes in East Asia and their uncertainty based on large ensemble simulations with a high-resolution AGCM. SOLA 13:7-12. https://doi.org/ 10.2151/sola.2017-002

Endo H, Kitoh A, Ose T, Mizuta R, Kusunoki S (2012) Future changes and uncertainties in Asian precipitation simulated by multiphysics and multi-sea surface temperature ensemble experiments with highresolution Meteorological Research Institute atmospheric general circulation models (MRI-AGCMs). J Geophys Res Atmos 117. https://doi. org/10.1029/2012JD017874

Gutowski WJ Jr, Giorgi F, Timbal B, Frigon A, Jacob D, Kang HS, Raghavan K, Lee B, Lennard C, Nikulin G, O'Rourke E, Rixen M, Solman S, Stephenson T, Tangang F (2016) WCRP COordinated Regional Downscaling EXperiment (CORDEX): a diagnostic MIP for CMIP6. Geosci Model Dev 9:4087-4095. https://doi.org/10.5194/gmd-9-4087-2016

Haarsma RJ, Roberts MJ, Vidale PL, Senior CA, Bellucci A, Bao Q, Chang P, Corti S, Fučkar NS, Guemas V, von Hardenberg J, Hazeleger W, Kodama C, Koenigk T, Leung LR, Lu J, Luo JJ, Mao J, Mizielinski MS, Mizuta R, Nobre P, Satoh M, Scoccimarro E, Semmler T, Small J, von Storch JS (2016) High Resolution Model Intercomparison Project (HighResMIP v1.0) for CMIP6. Geosci Model Dev 9:4185-4208. https:// doi.org/10.5194/gmd-9-4185-2016

Hall A (2014) Projecting regional change. Science 346:1461-1462. https://doi.org/ 10.1126/science.aaa0629

Harris I, Jones PD, Osborn TJ, Lister DH (2014) Updated high-resolution grids of monthly climatic observations -the CRU TS3.10 dataset. Int J Climatol 34: 623-642. https://doi.org/10.1002/joc.3711

He J, Soden BJ (2016) The impact of SST biases on projections of anthropogenic climate change: a greater role for atmosphere-only models? Geophys Res Lett 43:7745-7750. https://doi.org/10.1002/2016GL069803

Horel JD, Wallace JM (1981) Planetary-scale atmospheric phenomena associated with the Southern Oscillation. Mon Weather Rev 109:813-829. https://doi. org/10.1175/1520-0493(1981)109<0813:PSAPAW>2.0.CO;2

Huffman GJ, Adler RF, Morrissey MM, Bolvin DT, Curtis S, Joyce R, McGavock B, Susskind J (2001) Global Precipitation at One-Degree Daily Resolution from Multisatellite Observations. J Hydrometeor 2:36-50. https://doi.org/10.1175/ 1525-7541(2001)002<0036:GPAODD>2.0.CO;2

Imada Y, Maeda S, Watanabe M, Shiogama H, Mizuta R, Ishii M, Kimoto M (2017) Recent enhanced seasonal temperature contrast in Japan from large ensemble high-resolution climate simulations. Atmosphere 8:57. https://doi. org/10.3390/atmos8030057

Inatsu M, Sato T, Yamada TJ, Kuno R, Sugimoto S, Farukh MA, Pokhrel YN, Kure S (2015) Multi-GCM by multi-RAM experiments for dynamical downscaling on summertime climate change in Hokkaido. Atmos Sci Lett 16:297-304. https://doi.org/10.1002/as/2.557

IPCC (2012) Managing the risks of extreme events and disasters to advance climate change adaptation. In: Field CB, Barros V, Stocker TF, Qin D, Dokken DJ, Ebi KL, Mastrandrea MD, Mach KJ, Plattner G-K, Allen SK, Tignor M, Midgley PM (eds) A special report of working groups I and II of the intergovernmental panel on climate change. Cambridge: Cambridge University Press, p. 582.

IPCC (2013) Climate change 2013: the physical science basis. In: Stocker TF, Qin D, Plattner G-K, Tignor M, Allen SK, Boschung J, Nauels A, Xia Y, Bex V, Midgley PM (eds) Contribution of working group I to the fifth assessment report of the intergovernmental panel on climate change. Cambridge University Press, Cambridge and New York

Ito R, Ose T, Endo H, Mizuta R, Yoshida K, Kitoh A, Nakaegawa T (2020b) Seasonal characteristics of future climate change over Japan and the associated atmospheric circulation anomalies in global model experiments. Hydrol Res Lett 14:130-5. https://doi.org/10.3178/hrl.14.130.

Ito R, Shiogama H, Nakaegawa T, Takayabu I (2020a) Uncertainties in climate change projections covered by the ISIMIP and CORDEX model subsets from CMIP5. Geosci Model Dev 13:859-872. https:/doi.org/10.5194/gmd-13-859-2020

Kain JS, Fritsch JM (1990) A one-dimensional entraining/detraining plume model and its application in convective parameterization. J Atmos Sci 
47:2784-2802. https://doi.org/10.1175/1520-0469(1990)047<2784 AODEPM>2.0.CO;2

Karmalkar AV (2018) Interpreting results from the NARCCAP and NA-CORDEX ensembles in the context of uncertainty in regional climate change projections. Bull Am Meteorol Soc 99:bams-d-17-0127.1. https://doi.org/10. 1175/BAMS-D-17-0127.1

Kitoh A, Arakawa O (1999) On overestimation of tropical precipitation by an atmospheric GCM with prescribed SST. Geophys Res Lett 26:2965-2968. https://doi.org/10.1029/1999GL900616

Kitoh A, Endo $H$ (2016) Changes in precipitation extremes projected by a 20-km mesh global atmospheric model. Weather Clim Extreme 11:41-52. https://doi.org/10.1016/j.wace.2015.09.001

Kitoh A, Ose T, Takayabu I (2016) Dynamical downscaling for climate projection with high-resolution MRI AGCM-RCM. J Meteor Soc Japan 94A:1-16. https://doi.org/10.2151/jmsj.2015-022

Knutti R (2010) The end of model democracy? Clim Change 102:395-404 https://doi.org/10.1007/s10584-010-9800-2

Kusunoki S (2017) Future changes in global precipitation projected by the atmospheric model MRI-AGCM3.2H with a $60-\mathrm{km}$ size. Atmosphere 8. https://doi.org/10.3390/atmos8050093

Kusunoki S (2018) Is the global atmospheric model MRI-AGCM3.2 better than the CMIP5 atmospheric models in simulating precipitation over East Asia? Climate Dyn 51:4489-4510. https://doi.org/10.1007/s00382-016-3335-9

Kusunoki S, Mizuta R (2013) Changes in precipitation intensity over East Asia during the 20th and 21st centuries simulated by a global atmospheric model with a 60 km grid size. J Geophys Res Atmos 118:11:007-11:016. https://doi. org/10.1002/jgrd.50877

Maraun D (2016) Bias correcting climate change simulations-a critical review. Curr Clim Chang Rep 2:211-220. https://doi.org/10.1007/s40641-016-0050-x

McSweeney CF, Jones RG, Lee RW, Rowell DP (2015) Selecting CMIP5 GCMs for downscaling over multiple regions. Clim Dyn 44:3237-3260. https://doi.org/ 10.1007/s00382-014-2418-8

Mizuta R, Arakawa O, Ose T, Kusunoki S, Endo H, Kitoh A (2014) Classification of CMIP5 future climate responses by the tropical sea surface temperature changes. SOLA 10:167-171. https://doi.org/10.2151/sola.2014-2035

Mizuta R, Murata A, Ishii M, Shiogama H, Hibino K, Mori N, Arakawa O, Imada Y, Yoshida K, Aoyagi T, Kawase H, Mori M, Okada Y, Shimura T, Nagatomo T, Ikeda M, Endo H, Nosaka M, Arai M, Takahashi C, Tanaka K, Takemi T, Tachikawa Y, Temur K, Kamae Y, Watanabe M, Sasaki H, Kitoh A, Takayabu I, Nakakita E, Kimoto M (2017) Over 5,000 years of ensemble future climate simulations by $60-\mathrm{km}$ global and 20-km regional atmospheric models. Bull Am Meteor Soc 98:1383-1398. https://doi.org/10.1175/BAMS-D-16-0099.1

Mizuta R, Oouchi K, Yoshimura H, Noda A, Katayama K, Yukimoto S, Hosaka M, Kusunoki S, Kawai H, Nakagawa M (2006) 20-km-mesh global climate simulations using JMA-GSM model-mean climate states. J Meteor Soc Japan 84:165-185. https://doi.org/10.2151/jmsj.84.165

Mizuta R, Yoshimura H, Murakami H, Matsueda M, Endo H, Ose T, Kamiguchi K, Hosaka M, Sugi M, Yukimoto S, Kusunoki S, Kitoh A (2012) Climate simulations using MRI-AGCM3.2 with 20-km grid. J Meteor Soc Japan 90A: 233-258. https://doi.org/10.2151/jmsj.2012-A12

Okada Y, Takemi T, Ishikawa H, Kusunoki S, Mizuta R (2017) Future changes in atmospheric conditions for the seasonal evolution of the Baiu as revealed from projected AGCM experiments. J Meteor Soc Japan 95:239260. https://doi.org/10.2151/jmsj.2017-013

Ose T (2017) Future precipitation changes during summer in East Asia and model dependence in high-resolution MRI-AGCM experiments. Hydrol Res Lett 11:168-174. https://doi.org/10.3178/hrl.11.168

Ose T (2019) Characteristics of Future changes in summertime East Asian monthly precipitation in MRI-AGCM global warming experiments. J Meteor Soc Japan 97:317-335. https://doi.org/10.2151/jmsj.2019-018

Randall DA, Pan D-M (1993) Implementation of the Arakawa-Schubert cumulus parameterization with a prognostic closure. The representation of Cumulus convection in numerical models of the atmosphere. Meteor Monog 46:137-47.

Rayner NA, Parker DE, Horton EB, Folland CK, Alexander LV, Rowell DP, Kent EC, Kaplan A (2003) Global analyses of sea surface temperature, sea ice, and night marine air temperature since the late nineteenth century. J Geophys Res 108:4407. https://doi.org/10.1029/2002JD002670

Schneider U, Becker A, Finger P, Meyer-Christoffer A, Rudolf B, Ziese M (2016) GPCC full data reanalysis version 7.0: monthly land-surface precipitation from rain gauges built on GTS based and historic data. https://doi.org/10.5065/ D6000072

Šeparović L, Alexandru A, Laprise R, Martynov A, Sushama L, Winger K, Tete K, Valin M (2013) Present climate and climate change over North America as simulated by the fifth-generation Canadian regional climate model. Clim Dyn 41:3167-3201. https://doi.org/10.1007/s00382-013-1737-5

Shepherd TG (2014) Atmospheric circulation as a source of uncertainty in climate change projections. Nat Geosci 7:703-708. https://doi.org/10. $1038 /$ ngeo 2253

Smith I, Chandler E (2010) Refining rainfall projections for the Murray Darling Basin of south-east Australia-the effect of sampling model results based on performance. Clim Change 102:377-393. https://doi.org/10.1007/s10584-009-9757-1

Sun Q, Miao C, Duan Q, Ashouri H, Sorooshian S, Hsu K-L (2018) A review of global precipitation data sets: data sources, estimation, and intercomparisons. Rev Geophys 56:79-107. https://doi.org/10.1002/2017RG000574

Surendran S, Gadgil S, Rajendran K, Varghese SJ, Kitoh A (2019) Monsoon rainfall over India in June and link with northwest tropical pacific: June ISMR and link with northwest tropical pacific. Theor Appl Climatol 135:1195-1213. https://doi.org/10.1007/s00704-018-2440-6

Taylor KE (2001) Summarizing multiple aspects of model performance in a single diagram. J Geophys Res Atmos 106:7183-7192. https://doi.org/10.1029/ 2000JD900719

Taylor KE, Stouffer RJ, Meehl GA (2012) An overview of CMIP5 and the experiment design. Bull Amer Meteor Soc 93:485-498. https://doi.org/10. 1175/BAMS-D-11-00094.1

Urabe Y, Maeda S (2014) The relationship between Japan's recent temperature and decadal variability. SOLA 10:176-179. https://doi.org/10.2151/sola.2014-037

Wilby RL, Dessai S (2010) Robust adaptation to climate change. Weather 65:180185. https://doi.org/10.1002/wea.543

Xie P, Arkin PA (1997) Global precipitation: a 17-year monthly analysis based on gauge observations, satellite estimates, and numerical model outputs. Bull Amer Meteor Soc 78:2539-2558. https://doi.org/10.1175/15200477(1997)078<2539:GPAYMA>2.0.CO;2

Xie P, Chen M, Shi W (2010) CPC unified gauge-based analysis of global daily precipitation. In: Preprints 2.3A at the 24th conference on hydrology, Amer Meteor Soc 2010, Atlanta, US, 18 Jan 2010 https://ams.confex.com/ams/ 90annual/techprogram/paper_163676.htm. Accessed 20 May 2019

Yoshida K, Sugi M, Mizuta R, Murakami H, Ishii M (2017) Future changes in tropical cyclone activity in high-resolution large-ensemble simulations. Geophys Res Lett 44:9910-9917. https://doi.org/10.1002/2017GL075058

Yoshimura H, Mizuta R, Murakami H (2015) A spectral cumulus parameterization scheme interpolating between two convective updrafts with semiLagrangian calculation of transport by compensatory subsidence. Mon Weather Rev 143:597-621. https://doi.org/10.1175/MWR-D-14-00068.1

\section{Publisher's Note}

Springer Nature remains neutral with regard to jurisdictional claims in published maps and institutional affiliations.

\section{Submit your manuscript to a SpringerOpen ${ }^{\circ}$ journal and benefit from:}

- Convenient online submission

- Rigorous peer review

- Open access: articles freely available online

- High visibility within the field

- Retaining the copyright to your article

Submit your next manuscript at $>$ springeropen.com 